\title{
Numerical and Experimental Investigations on Vertical Axis Wind Turbines of Different Models
}

\author{
Mosfequr Rahman', Mahbub Ahmed ${ }^{2}$, Mohammad Bashar ${ }^{1}$, Aniruddha Mitra ${ }^{1}$, Travis Salyers ${ }^{1}$ \\ ${ }^{1}$ Georgia Southern University Statesboro, Statesboro, GA, USA \\ ${ }^{2}$ Southern Arkansas University Magnolia, Magnolia, AR, USA \\ Email: MahbubAhmed@saumag.edu
}

How to cite this paper: Rahman, M., Ahmed, M., Bashar, M., Mitra, A. and Salyers, T. (2017) Numerical and Experimental Investigations on Vertical Axis Wind Turbines of Different Models. Open Access Library Journal, 4: e3273.

http://dx.doi.org/10.4236/oalib.1103273

Received: December 1, 2016

Accepted: January 15, 2017

Published: January 18, 2017

Copyright (๑) 2017 by authors and Open Access Library Inc.

This work is licensed under the Creative Commons Attribution International License (CC BY 4.0).

http://creativecommons.org/licenses/by/4.0/

(c) (†) Open Access

\begin{abstract}
Wind is a free and abundant energy source and conversion of wind energy to electrical energy has no negative impact to the environment. Though the harvest of energy using a horizontal axis turbine (HAWT) is extremely common worldwide, the wind speed requirement is relatively high for power generation. On the contrary, a vertical axis wind turbine (VAWT) can produce power at low wind speeds as compared to the HAWT counterpart. In addition, a VAWT can produce power regardless of the wind direction and the installation of a VAWT is simple and more cost effective than a HAWT. The purpose of the current study is to compare performances among different VAWT models using both numerical and experimental methods and find the one with the optimum performance. Standard aero-foil blade designs were considered in the current study because of their good aerodynamic characteristics. The study was performed using both computational and experimental methods. The 2D CAD design of five different VAWT models including three aero-foil blades (NACA5510, NACA7510, and NACA9510) were performed using Solid Works. CFD simulation of wind flow around these models was performed using a popular software FLUENT using the moving mesh technique. The pressure and velocity contours as well as different coefficients such as lift coefficient, drag coefficient, torque coefficient, and power coefficient were obtained from this simulation for all VAWT models. In addition, the physical models of NACA 7510, NACA 5510, and semicircular VAWTs were fabricated and tested in a subsonic wind tunnel. At three different speeds, dynamic torques were measured for all models experimentally. The current study showed that the VAWT model with NACA 7510 blade yielded the best result among all the models at a relatively high tip speed ratio (TSR).
\end{abstract}

\section{Subject Areas}

Mechanical Engineering 


\section{Keywords}

Wind Energy, Vertical Axis Wind Turbine, Airfoil, Savonius Turbine, Tip Speed Ratio, Power Coefficient, CFD

\section{Introduction}

\subsection{Background of Wind Turbine}

Efficient conversion of wind energy into electricity can resolve the power demand of the entire world. Wind is going to be the most popular alternative energy source because of its availability throughout place and time. Wind is getting importance in energy policy as a pollution free and sustainable source of energy. The disadvantages include its relatively low efficiency and high installation cost. However, the ultimate cost could be lowered if it operated continuously. Another aspect is that a small-scale turbine can be installed in any corner of the world. Wind turbines convert wind energy into mechanical energy and that mechanical energy is used for the production of electricity. There are two types of primary wind turbines-horizontal-axis wind turbines (HAWT) and vertical-axis wind turbines (VAWT); both types have their own advantages and disadvantages.

HAWTs include both upwind and downwind configurations with various performance enhancers such as diffusers and concentrators. HAWTs are more popular because they have better efficiency, but they are only suitable for places with high wind speeds. In contrast, a VAWT works well in places with relatively lower wind speeds [1]. The blades do not need to be oriented for a VAWT to go with the wind direction since it can always work despite the direction of the wind [2].

Due to better aerodynamic behavior and better efficiency in the large scale, a HAWT was the popular choice of the researchers. The factors that attracted the researchers towards VAWTs include the following: 1) a VAWT is more appropriate than a HAWT in small scale, 2) VAWTs are suitable for electricity generation in conditions where traditional HAWTs are unable to give reasonable efficiencies such as low wind velocities and turbulent wind flows, 3) a VAWT can operate without any dependency on wind direction, 4) the quietness is more attractive for highly populated places, 5) the cost of the complex structure of HAWT blades is higher than the simpler VAWT blades, 6) because of their stalling behavior a VAWT can withstand gust wind, making it much safer during those weather conditions, 7) this type of rotor can be installed in remote places, away from the main distribution lines and places where large wind farms cannot be installed due to environmental concerns, 8) some places need small scale dispersed generation units [3] and, VAWTs are more advantageous than their HAWT counterparts in these areas. In general, a VAWT is driven by two types of forces of wind -drag force and lift force. Being a drag type configuration, Sa- 
vonius is the simplest among all VAWTS; while Darrieus being a lift type VAWT has a more complex working principle.

\subsection{Review on Vertical Axis Wind Turbine}

Optimum output from the wind energy is the key objective of most studies in the past in this area and different aerodynamic shaped VAWT blades have been investigated for this purpose. Numerous investigations have been carried out previously to study the performance characteristics of Savonius rotors. These investigations included wind tunnel tests, field experiments, and numerical studies. Blade configurations were studied in wind tunnels to evaluate the effect of aspect ratio, number of blades, overlap, and gap between blades, effect of adding end extensions, end plates, and shielding.

The operation of a Savonius rotor depends on the difference of drag forces when the wind strikes the concave and the convex parts of the semi-spherical blades. The flow energy utilization of a Savonius rotor is lower than that of a Darrieus rotor. Hence, this type of turbine has limited uses for high-power applications andit is often used for wind velocimetry applications [4]. However, the greatest advantage of a Savonius rotor is its ability to self-start in contrast to other "Lift type" VAWTs [5].

Blade overlapping affects the performance of a Savonius turbine. In a study, the performance of a two bladed Savonius turbine with five overlaps of $16.2 \%$, $20 \%, 25 \%, 30 \%$, and $35 \%$ were investigated [6] and among them, the $16.2 \%$ overlap condition showed the maximum power extraction. In the same study, the pressure drop across the rotor from upstream to downstream as well as, maximum pressure difference across the returning bucket was displayed at the same condition that eventually indicated the better overall aerodynamic torque and power. The three bladed Savonius rotor with different overlap ratios was investigated in another experimental study [7] where the ratios of 0.0, 0.12, and 0.26 were used for different Reynolds numbers (Re). The model with no overlap ratio showed better torque coefficients for a lower Re and better power coefficients at a higher Re and with the increase of tip speed ratio. Some researchers focused on more innovative type blades in this area. Qasim et al. [8] worked with a scoop-frame type impeller with movable vane VAWT. The objective was to maximize the drag factor by closing the vanes when air hit the convex portion and opening them when air hit the concave part. Due to the movement of vanes to and against the wind, a higher drag factor as well as higher efficiency were found on the impeller with a scoop-frame and movable vanes than that of an impeller with regular flat vanes. Manzoor et al. [9] experimented on Savonius rotors to compare the performance of twisted blades. Initially they carried out the experiment with two vertical, semi-circular curved blades and then with twisted blades with angles ranging from $0^{\circ}$ to $60^{\circ}$. From the analysis of wind flow over various configurations of the rotor blades, they found that the maximum efficiency was $33.85 \%$ at $\theta=45^{\circ}$ as compared to $25.6 \%$ at $\theta=0^{\circ}$. Both the RPM and torque were also found to be higher in the same study with twisted 
blades as compared to their non-twisted counterparts. As the overall projected area increases due to the twist, it causes a positive impact to the overall performance of the VAWT. It is perceived that twisted blades attribute relatively higher drag on the turbine surface and yield better overall performances as compared to the non-twist ones. Another similar study was performed by Ghatage and Joshi [10] that investigated VAWT performance with twisted blades as well as with different numbers of blades. Their study found that two blades with twist enhanced the efficiency of the turbine and the optimum power coefficient was obtained at a twist angle of $30^{\circ}$.Kumbernuss et al. [11] studied two-staged Savonius-type turbines by varying the number of blades, the shape of the blades, the overlap ratio, and the phase shift angle while the tests were conducted under four different wind speeds of $4 \mathrm{~m} / \mathrm{s}, 6 \mathrm{~m} / \mathrm{s}, 8 \mathrm{~m} / \mathrm{s}$, and $10 \mathrm{~m} / \mathrm{s}$. Their study showed that out of three overlap ratios of $0,0.16$, and 0.32 , the turbine with the overlap ratio of 0.16 produced the best performance followed by the turbine with the overlap ratio of 0.32 . Saha et al. [12] conducted a wind tunnel test to assess the aerodynamic performance of Savonius rotor systems with different stages where both semicircular and twisted blades had been used in each case. Experiments were carried out to optimize the different parameters like number of stages, number of blades (two and three), and geometry of the blade (semicircular and twisted). It was concluded from their research that the two-stage rotor showed better performance characteristics when compared to the three-stage one. The turbine performance decreases as the inertia increases by increasing the number of stages. Rahman et al. [13] performed an investgation on the drag and torque characteristics of three bladed Savonius wind turbines and found better drag and torque characteristics for the turbines with no overlaps. For the same study, through a CFD analysis, it was found that a higher Reynolds number yielded better aeorodynamic behaviour for no overlaping blades. Another study performed by Morshed et al. [14] showed that for a three-bladed Savonius wind turbine, the change of the blade shape can have a real impact on the performance and a better aerodynamic coefficient was found at a higher Reynolds number without any overlap. A fully automated process for optimizing the air foil cross-section of a VAWT was introduced and demonstrated by Carrigan et al. [15] where the objective was to maximize the torque while enforcing typical wind turbine design constraints such as tip speed ratio, solidity, and blade profile.

Like Savonius, many studies focused on finding the optimal performance of Darrieus rotor as well. These investigations include mostly numerical studies. However, some focused on testing of Darrieus models in wind tunnels as well as in a real life everyday environment. Aerodynamic characteristics were studied to evaluate the effect of blade shape and angle, material, and configurations. Some researchers tried to change the external factors to improve the starting characteristics of Darrieus rotor. Howell et al. [16] performed research on a small scale Darrieus rotor where a combined experimental study in a wind tunnel as well as a computational study was done to find the aerodynamics and performance at 
different wind velocity, tip-speed ratio, solidity, and rotor blade surface finish. Their study found that, below a critical wind speed (Reynolds number of 30,000) a smooth rotor surface finish degraded the performance of the turbine. Their research also showed that both two and three bladed rotor models produced highest performance coefficient, where the three bladed models did so at a much-reduced Tip Speed Ratio. Beri and Yao [17] studied a three bladed selfstarting Darrieus turbine with NACA 2415 camber airfoil and investigated the performance at different tip speed ratio. Their study showed that the camber airfoil has the characteristics of a self-starter, though for the same power coefficient the efficiency was less than the non-self-starting airfoils. Hameed and Afaq [18] designed a straight symmetrical blade for a small-scale Darrieus rotor using beam theories in an investigation where they changed the design parameters such as solidity, aspect ratio, and pressure coefficient. Their study showed that keeping the maximum stresses and deflection within acceptable range, the wall thickness of the blade could be optimized by reducing weight of the blade. Armstrong et al. [19] investigated the aerodynamics of a full size functional turbine with high solidity Darrieus rotor experimentally in a wind tunnel at Re > 500,000 and found that straight blades and canted blades have different flow separation behaviors. Canted blades experienced less flow reversal on their upwind pass and recovered the attached flow before $\theta=180^{\circ}$. In addition, the Canted blades increased the power and reduced the blade speed ratio at which peak power occurred. Their study also showed that the addition of fences, which acted to impede span wise flow on the swept blades, reduced the blade speed ratio at peak power of about $\lambda=1.9$, presumably with a flow that is more similar to the straight blade case. Castelli et al. [20] presented a model for the evaluation of aerodynamic and inertial contributions to a VAWT blade deformation. They made the geometries of the blades using a solid modeling tool based on the design parameters and with the provision of using finite volume and finite element methods for investigating the rotor performance and structural analysis of the rotor blades respectively. In their study, the flow field characteristics were investigated for a constant unperturbed free-stream wind velocity of $9 \mathrm{~m} / \mathrm{s}$ to determine the torque coefficient generated from the three blades. They suggested further investigation on the influence of this blade section deformation on the aerodynamic performance. Combined Savonius-Darrieus rotors were also focus of some researchers. Gupta et al. [21] compared the performance of such a combined turbine with a simple Savonius one. The Savonius rotor was a threebucket system having provisions for overlap variations whereas the SavoniusDarrieus rotor was a combination of three-bucket Savonius and three-bladed Darrieus rotors with the Savonius one being placed on top of the Darrieus one. Their comparative study showed that the combined turbine had a relatively higher efficiency as compared to that of Savonius one under the same test conditions.

It is apparent that many researchers have been investigating different characteristics of VAWTs to improve the overall efficiencies as well as to find out op- 
timum designs that can provide maximum outputs. Scientists are using both numerical and experimental approaches to find the optimum number of blades, efficient blade design, optimum overlap ratio and optimum number of layers for Savonius rotors. As well, many researchers are investigating the aerodynamic behavior of the blades of VAWT to increase the starting torque value. However, the authors of the current study feel that a comprehensive dynamic study using both experimental and numerical methods has not been extensively studied on airfoil with VAWT blade design, if studied at all.

\subsection{Goal and Objectives of the Research}

The goal of this research is to find highly efficient VAWT models by studying the aerodynamic characteristics of various VAWT models with airfoil shaped and non-airfoil shaped cross-sections of blades for Savonius rotors. In order to investigate the performance improvement of VAWTs the current research has the objectives to: 1) design various VAWT models using the CAD tools SolidWorks and ANSYS; 2) generate numerical mesh of the turbine models using FLUENT; 3) create fluid flow fields of the models using $k$ - $\mathcal{E}$ turbulence model using FLUENT; then determine the drag coefficient, lift coefficient, pressure contours, velocity contours, and torque coefficient at various wind speed; 4) calculate the numerical power coefficient from the torque coefficient; 5) design and fabricate Savonius rotor wind turbine scale physical models with optimum blade numbers and selected shapes; 6) Measure torques in a subsonic wind tunnel for three models at different wind speeds using a dynamic torque sensor; 7) calculate torque and power coefficients from experimental values; and 8) compare the numerical and experimental results.

\section{Methodology}

The foremost part of this research is numerical investigation, which was performed using ANSYS-FLUENT software. The flow field was designed for twodimensional models. The mesh was generated using ANSYS and a basic investigation was performed using FLUENT to determine the aerodynamic coefficients; such as drag, lift, and torque coefficients. Values of forces, velocities, and torques were recorded and then used to calculate torque and power coefficients. The next step was to fabricate three physical models of VAWT and test them inside of a subsonic wind tunnel at different wind speeds. Torque, wind speed, and rotational speed were measured and subsequently torque and power coefficients were calculated. Numerical and experimental results were then compared to make conclusions.

\subsection{Numerical Method}

Creating the geometries of the VAWT models was the first step in performing the numerical simulation. Different VAWT models have been created using Solid Works and ANSYS for this purpose. These geometries, defined as sets of Cartesian coordinates, were passed to the mesh generation modules to discretize 
the flow fields. As part of the numerical analysis, FLUENT 2-D was used on five different models at different wind speeds and results were compared with each other.

\subsubsection{Blade Profiles}

Five different models were created for this numerical analysis as mentioned before. The overall diameter and the central shaft diameter for each model were 8.5 inch and 0.5 respectively. Five different blade profiles were semi-circular, quarter-circular, and three airfoils of NACA5510, NACA7510, and NACA9510. A comparative view of NACA 5510, NACA7510, and NACA9510 are shown in Figure 1.

The basic semi and quarter circular shapes were experimented in many researches in the past, which helped to compare the basic shapes with airfoil shapes. NACA 4-digit airfoil series is a popular way to create airfoils. The first two digits indicate the maximum camber as the percentage of the chord and the position of the maximum camber in tenth of the chord respectively. The last two digits provide the maximum thickness as percentage of the chord. The position of the camber and the thickness were kept constant while the maximum camber was varied in this study. Isometric views of all five-blade profiles are shown in Figure 2.

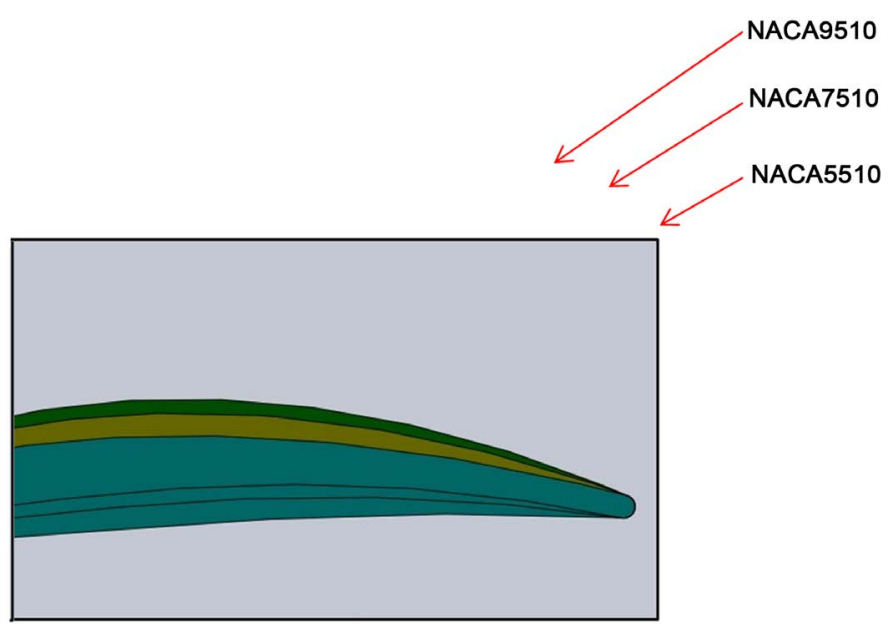

Figure 1. A comparative view of NACA profiles.

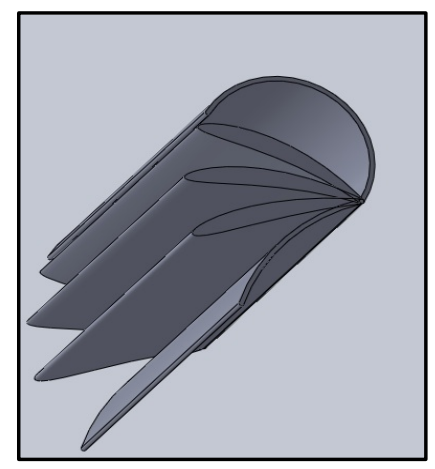

Figure 2. Isometric view of all five blades. 
The three dimensional CAD software Solid works was used to create all five turbine models. Isometric view of three rotor models using NACA5510, NACA7510, and NACA9510 airfoils can be seen in Figure 3. Then ANSYS Design Modeler was used to make the 2-D profiles of all models.

\subsubsection{Mesh Generation}

A mesh was generated around a rotor using ANSYS Mesh as shown below in Figure 4 . The exit of the wind tunnel was considered the inlet of the computational domain.

The rotor was placed in an environment where the environment and the rotor were separated by an interface. This interface was required to implement the sliding mesh mechanism. Total number of nodes generated for NACA5510, NACA7510, NACA9510, quarter-circular, and semi-circular cross-sectional bladed five different turbine models were 5476, 6077, 6137, 6675, and 6437 respectively. CFD FLUENT solver was used to create these meshes. The orthogonal grid refinement was implemented around the rotor blade and the interface that creates a smooth transition of meshes from the inlet towards the down-
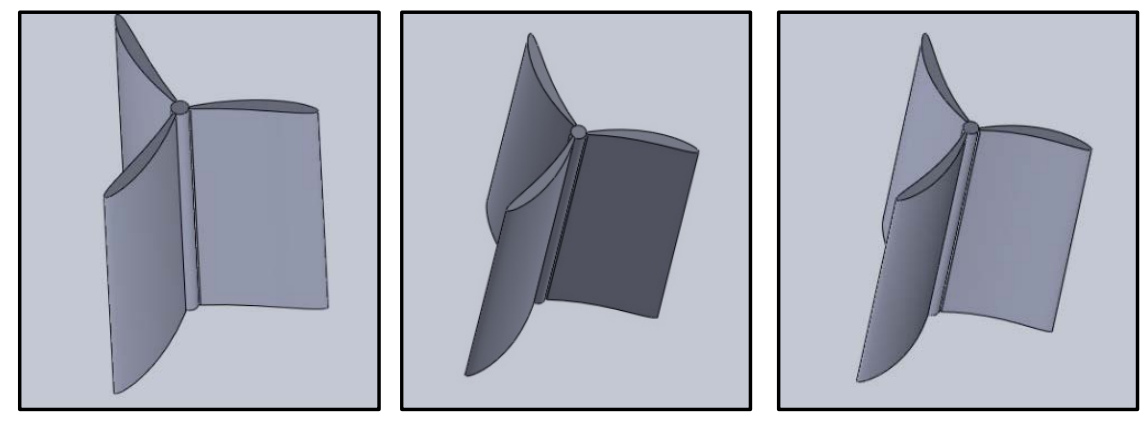

Figure 3. Isometric views of three rotor models using NACA5510, NACA7510, and NACA9510 airfoils respectively.

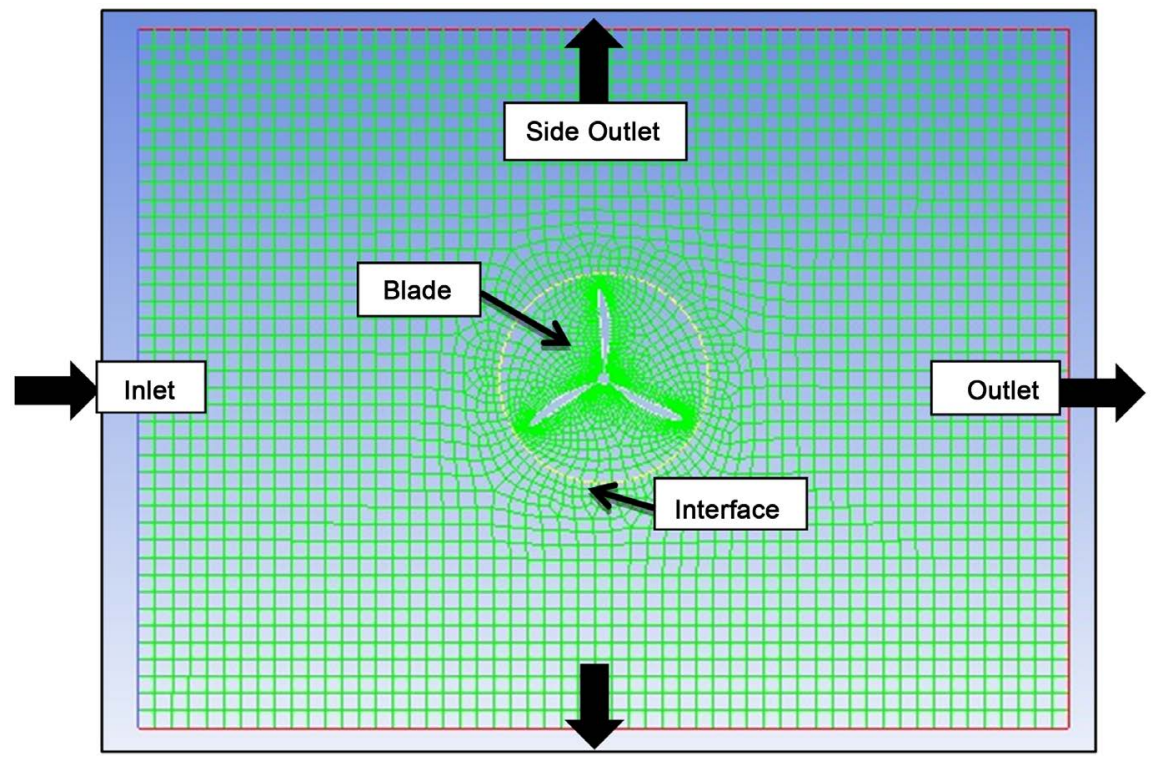

Figure 4. 2D mesh around an airfoil using ANSYS. 
stream side in the radial direction for a more realistic computation of airflow. The inlet, outlet, and side outlets (top and bottom) are indicated in the figure. All five models considered in this numerical simulation were three bladed as it is experimentally proven in various researches that a three bladed turbine provides a better power coefficient. The overall size of the two-dimensional computational domain was 40 in $\times 30$ in.

\subsubsection{Numerical Procedure}

The left side of the grid was assigned as the inlet considering that air flowing in one direction hits the rotor blade causing the rotation of the rotor. The right side of the grid was chosen to be the main outlet while the top and bottom were considered as side outlets with atmospheric pressure conditions. Four different air velocities of $10 \mathrm{~m} / \mathrm{s}, 11 \mathrm{~m} / \mathrm{s}, 12.5 \mathrm{~m} / \mathrm{s}$, and $15 \mathrm{~m} / \mathrm{s}$ were considered at the inlet. Blades were considered as a moving wall. For uniformity of the results, all the models were kept at same starting positions.

The environment where the air flowed around the rotor was assumed turbulent. The momentum, turbulent kinetic energy, and dissipation rate were calculated using the Second Order Upwind method. Numerical simulation provided the pressure and velocity values at all nodal points of flow domain around the rotating blades. The same convergence criteria were used for all the models in case of continuity, $\mathrm{X}$ and $\mathrm{Y}$ velocity, Kinetic energy $(\mathrm{k})$ and dissipation rate $(\mathcal{\varepsilon})$.

A systematic iterative numerical study on various cross-sections of the blades was performed using the commercial software package ANSYS FLUENT. Pressure based solver and transient solution were used to simulate airflow around the rotor. Sliding mesh technique was used to rotate the rotor. The pressure-velocity coupling was achieved using the well-known SIMPLE (Semi-Implicit Method for Pressure-Linked Equations) method by Patankar [22]. The standard $k-\mathcal{E}$ turbulence model in FLUENT was used for the analysis of turbulent flow around the rotor models. Turbulent kinetic energy $(k)$ and turbulent dissipation rate $(\varepsilon)$ first order upwind scheme were chosen for the momentum equation solution. The standard $\mathrm{k}-\mathcal{E}$ turbulence model [23] is a semi-empirical model based on model transport equations for turbulence kinetic energy $(k)$ and its dissipation rate $(\varepsilon)$. The model transport equation for $\mathrm{k}$ was derived from the exact equation, while the model transport equation for $(\varepsilon)$ was obtained using physical reasoning and bears little resemblance to its mathematically exact counterpart.

The turbulence kinetic energy, $k$, and its rate of dissipation, $\mathcal{E}$, were obtained from the following transport equations:

$$
\begin{array}{r}
\frac{\partial}{\partial t}(\rho k)+\frac{\partial}{\partial x_{i}}\left(\rho k u_{i}\right)=\frac{\partial}{\partial x_{j}}\left[\left(\mu+\frac{\mu_{t}}{\sigma_{k}}\right) \frac{\partial k}{\partial x_{j}}\right]+G_{k}+G_{h}-\rho \varepsilon-Y_{M}+S_{k} \\
\frac{\partial}{\partial t}(\rho \varepsilon)+\frac{\partial}{\partial x_{i}}\left(\rho \varepsilon u_{i}\right)=\frac{\partial}{\partial x_{j}}\left[\left(\mu+\frac{\mu_{t}}{\sigma_{\varepsilon}}\right) \frac{\partial \varepsilon}{\partial x_{j}}\right]+c_{1 \varepsilon} \frac{\varepsilon}{k}\left(G_{k}+C_{3 \varepsilon} G_{b}\right)-C_{2 \varepsilon} \rho \frac{\varepsilon^{2}}{k}+S_{\varepsilon}
\end{array}
$$

In these equations, $G_{k}$ represents the generation of turbulence kinetic energy due to the mean velocity gradients, $G_{b}$ is the generation of turbulence kinetic 
energy due to buoyancy, $Y_{M}$ represents the contribution of the fluctuating dilatation in compressible turbulence to the overall dissipation rate, and $C_{1 \varepsilon} C_{2 \varepsilon}$ and $C_{3 \varepsilon}$ are constants. In addition, $\sigma_{K}$ and $\sigma_{\varepsilon}$ are turbulent Prandtl numbers for $\mathrm{k}$ and $\varepsilon$ respectively and $S_{k}$ and $S_{\varepsilon}$ are user-defined source terms. The turbulent (or eddy) viscosity, $\mu_{b}$ is computed by combining $\mathrm{k}$ and $\varepsilon$ as follows:

$$
\mu_{t}=\rho C_{\mu} \frac{k^{2}}{\varepsilon}
$$

where $C_{\mu}$ is a constant.

For transient solution, after a few time-steps the residuals showed the same patterns. After 2 - 3 seconds, all the models showed a pattern for convergence. As a rotating device, all the characteristics displayed sinusoidal curves for the residuals. However, the main characteristic on which the steadiness depends on for all the models is the kinetic energy $(k)$. The residual of kinetic energy changed suddenly from low to high and then back to low again. After that, with time it remained steady for the steady wind flow. Velocity provided the main role behind the kinetic energy. Continuity and Epsilon has little change over the time. NACA profile bladed rotors were unsteady for lower wind speed for almost 5 seconds. With increment of wind speed, a pattern was developed after 2 3 seconds. On the other hand, for the rotor with the circular shaped blades the steady pattern developed soon for all four-wind speeds.

\subsection{Experimental Design}

The experiment was carried out under different wind speeds on different blade shapes of the VAWT models in an in-house subsonic wind tunnel. The NACA 4-digit series was chosen to create airfoil. This type of airfoil has good aerodynamic characteristics such as good stall characteristics, low roughness effect, relatively high drag, and low lift coefficient that match the characteristics of Savonius type VAWT as well. The analytical equations describe the camber (curvature) of the mean-line (geometric centerline) of the airfoil section and the distribution of section thickness along the length of the airfoil.

The blades were placed $120^{\circ}$ apart for the rotor models. The whole turbine model assembly was installed in a frame. The same experimental setup was also portrayed in computational simulation. The models were then tested using the interchangeable design with varying wind speeds of $10 \mathrm{~m} / \mathrm{s}, 11.5 \mathrm{~m} / \mathrm{s}$, and 12.5 $\mathrm{m} / \mathrm{s}$. These wind speeds produced a varying degree of angular speeds of the rotor and torques. The torque and angular speed were measured using the torque sensor and tachometer respectively. The effect of temperature can be ignored in this measurement technique as the experiment was carried out at atmospheric pressure and temperature. For regular room temperature the air density and the air viscosity were considered as $\rho=1.2 \mathrm{~kg} / \mathrm{m}^{3}$ and $\mu=1.983 \mathrm{~kg} / \mathrm{ms} \cdot 10^{-5}$ respectively.

\subsection{Mathematical Relations}

The power in this study was estimated as the rate of change of angular momen- 
tum of wind stream. The tip speed ratio $(\lambda)$ was calculated using the measured angular speed using Equation (7). Power produced by the rotor was calculated from measured torque and angular speed using Equation (10). The torque coefficients $\left(C_{q}\right)$ can be calculated using the measured dynamic torque data using Equation (11) for all models. Power coefficient can be calculated using the measured torque and angular velocity of the rotor using Equation (12).

$$
\begin{aligned}
& \text { Rotor Area: } A=D \cdot H \\
& \text { Angular Velocity: } \omega=\frac{2 \pi N}{60} \\
& \text { Reynolds Number: } \operatorname{Re}=\frac{V D}{v} \\
& \text { Tip Speed Ratio: } \lambda=\frac{\omega D}{2 V} \\
& \text { Drag Coefficient: } C_{d}=\frac{F_{d}}{0.5 \rho A V^{2}} \\
& \text { Lift Coefficient: } C_{l}=\frac{F_{l}}{0.5 \rho A V^{2}} \\
& \text { Power: } P=T \omega \\
& \text { Torque Coefficient: } C_{q}=\frac{T}{0.5 \rho A V^{2} R} \\
& \text { Power Coefficient: } C_{P}=\frac{P}{0.5 \rho A V^{3}}
\end{aligned}
$$

\subsection{Experimental Method}

Blades and the corresponding models were manufactured similar to the computational analysis and those rotors were tested in front of the wind tunnel at varying wind speeds. The detailed descriptions are given as follows.

\subsubsection{Subsonic Wind Tunnel}

The subsonic wind tunnel as shown above in Figure 5 was 12 feet long consisting a converging mouth entry, a honeycomb section at the inlet side, a fan section, a rectangle test section, a honeycomb section at the exit side, a converging diverging section and a rectangular exit section. The airflow was generated using a variable frequency axial flow fan inside the tunnel and the air velocity was controlled using a variable frequency drive. The converging mouth entry was designed for an easy entry of air in the tunnel as well as to maintain a uniform flow through it. The first honeycomb section was used to reduce the swirling effect and make the flow straight. The second honeycomb section was also used to keep the flow straight through the test section. The converging and diverging section helped to minimize the expansion and contraction loss and to reduce the possibility of flow separation. The exit section was used to make the flow straight and uniform. 

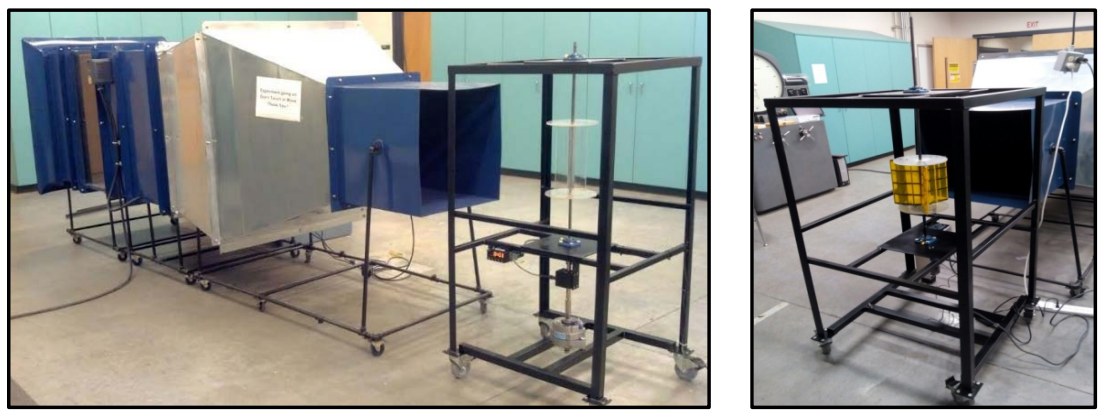

Figure 5. A complete experimental setup of the wind tunnel.

\subsubsection{Rotor Models}

Based on the CFD simulation results, various VAWT scale models were designed and manufactured. Three of the manufactured rotors were semi-circular, NACA5510, and NACA7510. The models of both NACA5510 and NACA7510 were made of three blades of diameter, $d=5$ inches and height, $H=10$ inches. The turbine models were made of film-coated wood and with a central shaft of stainless steel with a diameter of 0.5 inches. The blades were $120^{\circ}$ apart from each other and the overall rotor diameter was $D=10.5$ inches. The two discs holding the blades were made of acrylic plastic. The fabricated NACA5510 airfoil bladed turbine scale model is shown in Figure 6 and the fabricated semicircular bladed wind turbine's scale model is shown in Figure 7. The semicircular model was made of three semi-cylindrical blades of diameter, $d=4.75$ inches, and height, $H=11.5$ inches. The turbine model was made of acrylic without any central shaft. The blades were $120^{\circ}$ apart from each other and the overall rotor diameter was $D=9.75$ inches.

During the testing procedure, these rotor models were placed in front of the tunnel, at 15 inches downstream from the outlet to ensure a uniform wind flow, with supporting shafts at both upper and lower sides of the models. The models were placed around both vertical and horizontal axes of the cross section. These blade models were able to rotate freely around the shaft supports with ball bearing collars.

\subsubsection{Experimental Procedure}

The experiments were carried out at three different wind speeds of $11.3 \mathrm{~m} / \mathrm{s}, 11.7$ $\mathrm{m} / \mathrm{s}$, and $12 \mathrm{~m} / \mathrm{s}$. Wind speeds were measured by a handheld anemometer at different locations at a distance of 15 inches from the outlet of wind tunnel around the rotor. The average wind velocity around the rotor was taken into account while doing the calculations.

A dynamic rotary torque transducer (Model: T8 ECO) was used to measure the torque $(T)$. The rotor was coupled on the driving side of the transducer and a constant breaking load was applied on the other side that helped to measure the torque. A drop bracket was fabricated that held the sensor and the break underneath in a location that allowed for smooth coupling and easy rotation with the bottom of the main shaft. A bench top display (DP41-B) was added to the setup as a means of reading real-time torque output via signals transmitted from the 


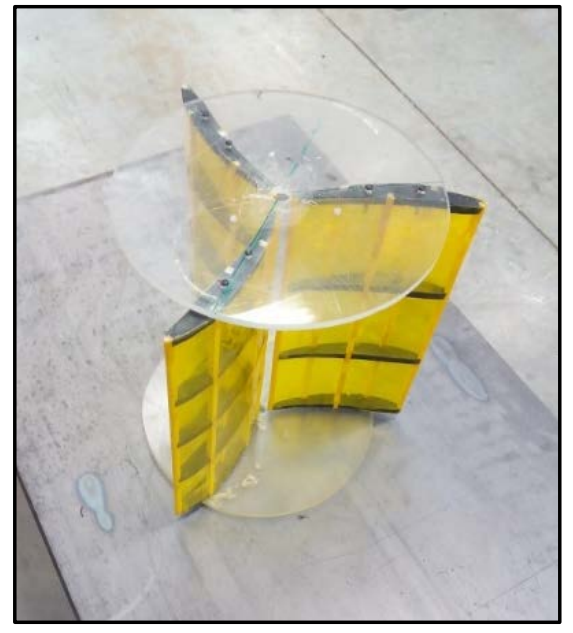

Figure 6. Fabricated model of NACA5510 aero-foil rotor (three bladed).

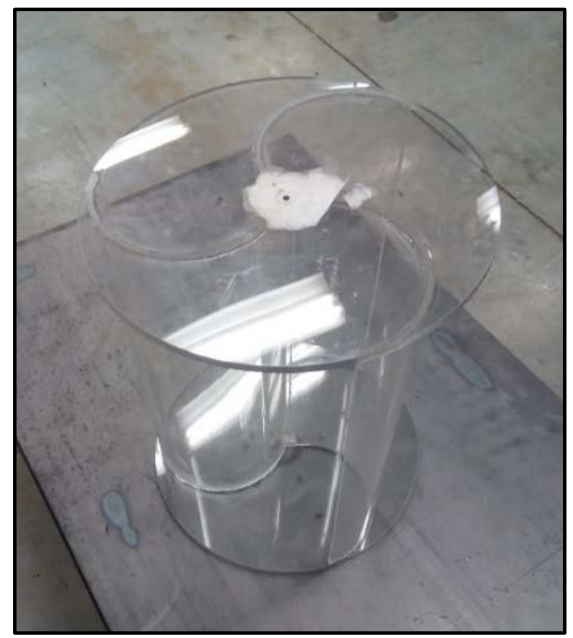

Figure 7. Fabricated model of semi-circular rotor (three bladed).

compatible torque sensor. The rotational speed of the rotor $(N)$ was measured by a non-contact handheld photo tachometer.

\subsubsection{Measured Characteristics}

Numerical study provided the drag, lift, and torque coefficients. The force and moment on the blade wall were also directly extracted from the simulation. Angular velocity $(\omega)$ was calculated from the measured rotational speed using Equation (5). These parameters were then used to calculate the tip speed ratio, the Reynolds number, the torque coefficient, and the power coefficient.

\section{Results}

\subsection{Numerical Results}

\subsubsection{Pressure Contours}

The pressure contours with corresponding maximum and minimum values obtained from the numerical results for all five models are shown in Figures 8-12 at time $t=5$ seconds. Differential pressures observed between the concave and 


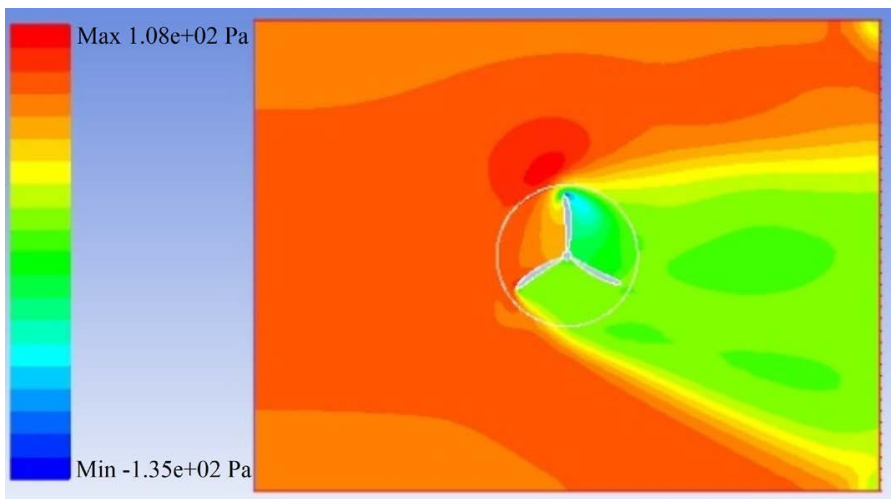

(a)

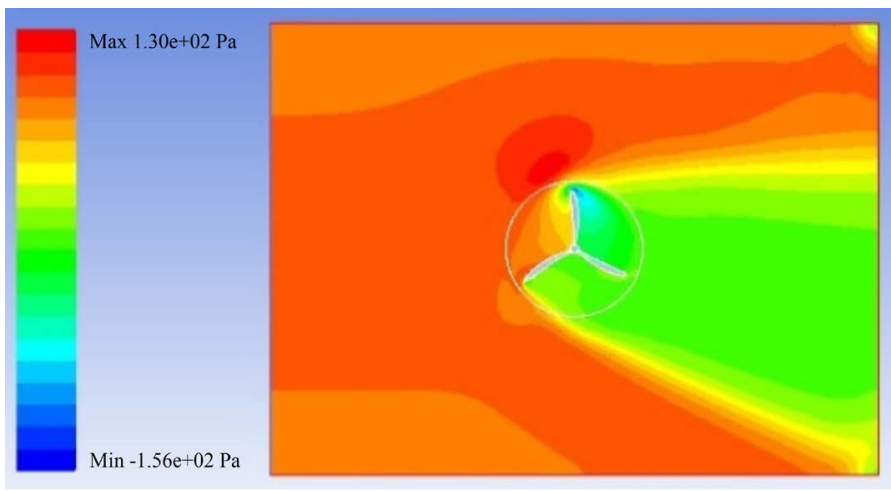

(b)

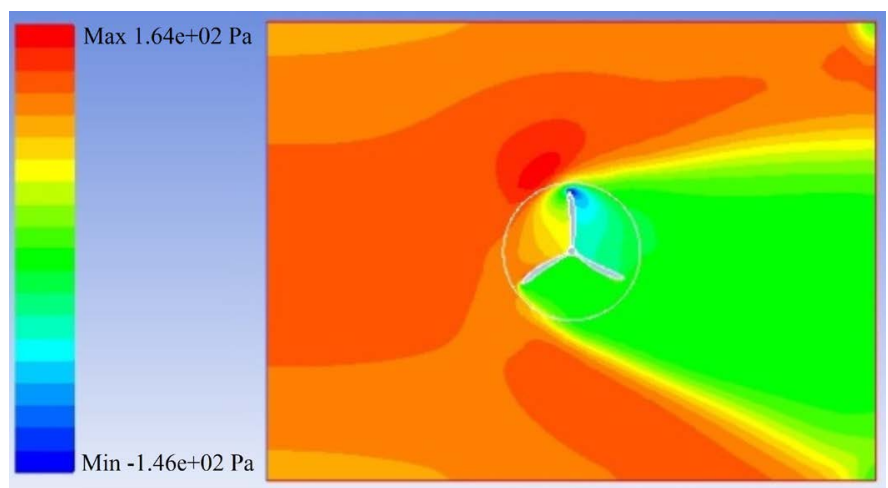

(c)

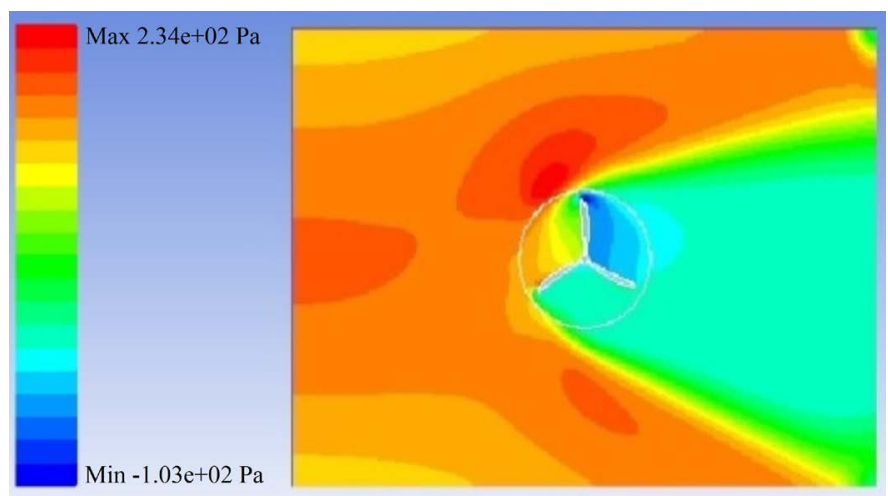

(d)

Figure 8. Pressure contour around NACA5510 model (three bladed) at TSR (a) 0.226, (b) 0.247 , (c) 0.271 and (d) 0.301 . 


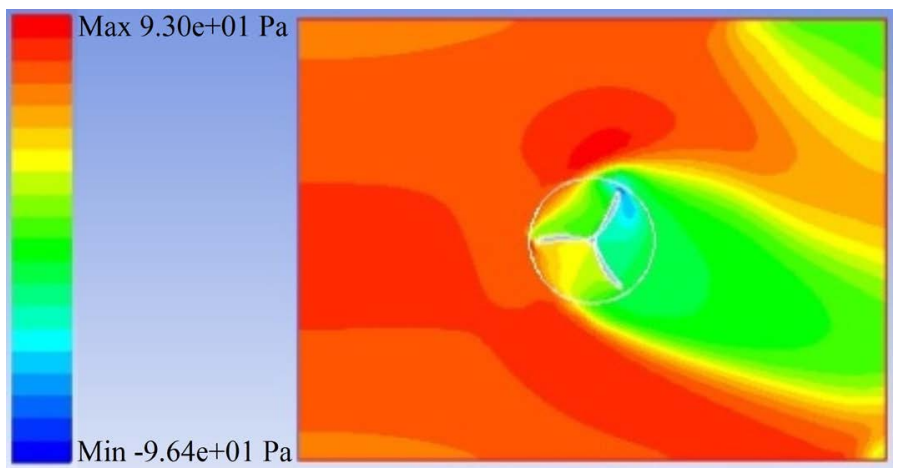

(a)

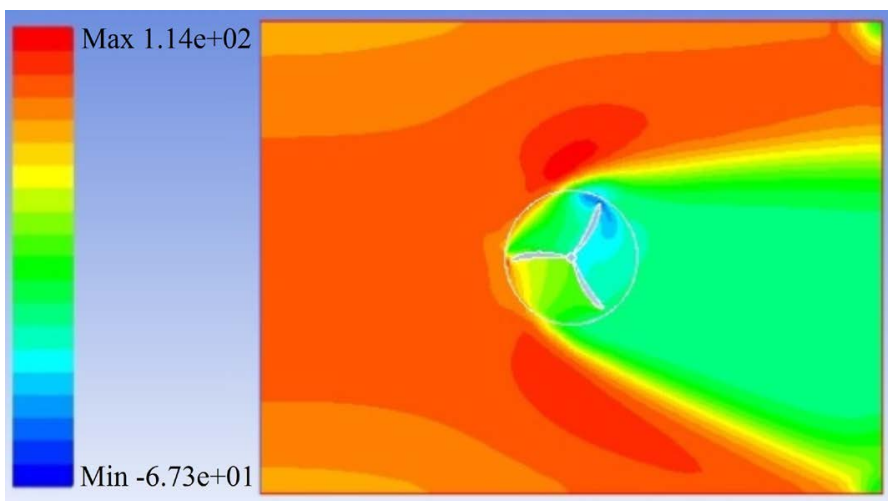

(b)

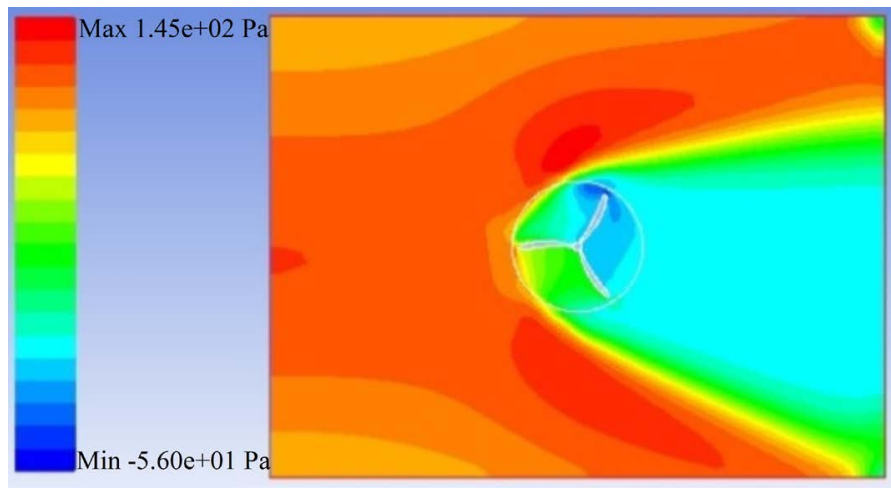

(c)

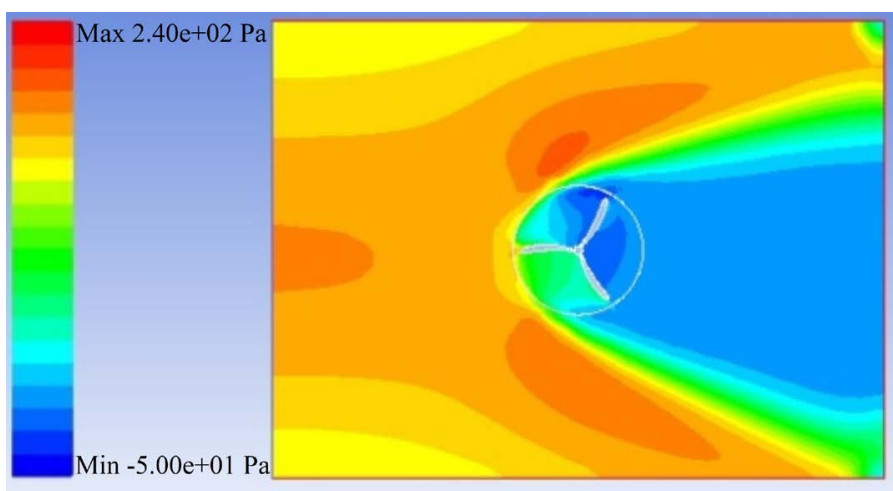

(d)

Figure 9. Pressure contour around NACA7510 model (three bladed) at TSR (a) 0.226 , (b) $0.247,(c) 0.271$ and (d) 0.301 . 


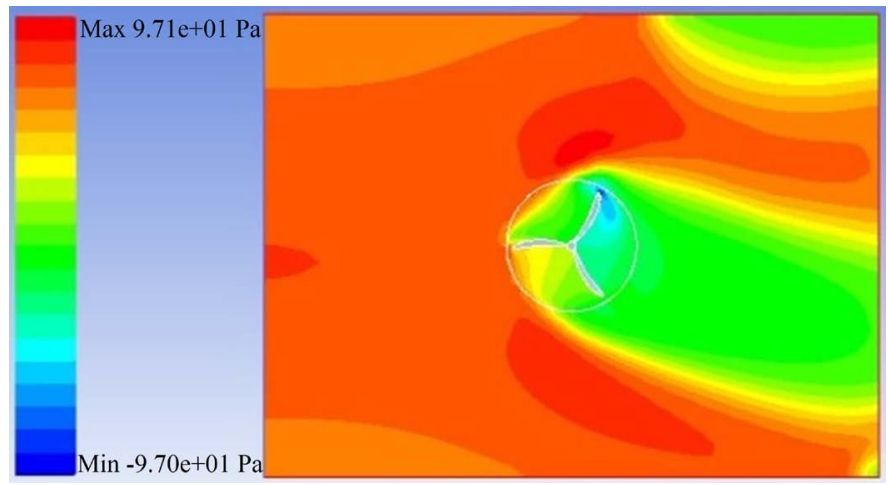

(a)

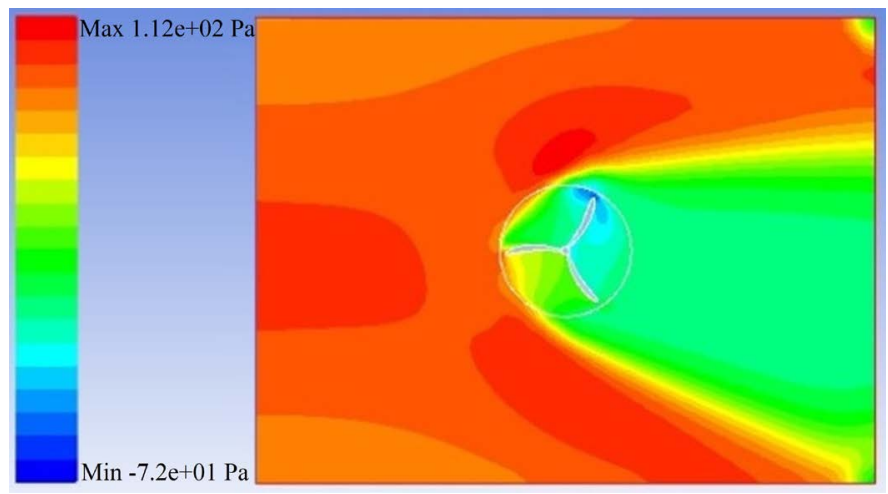

(b)

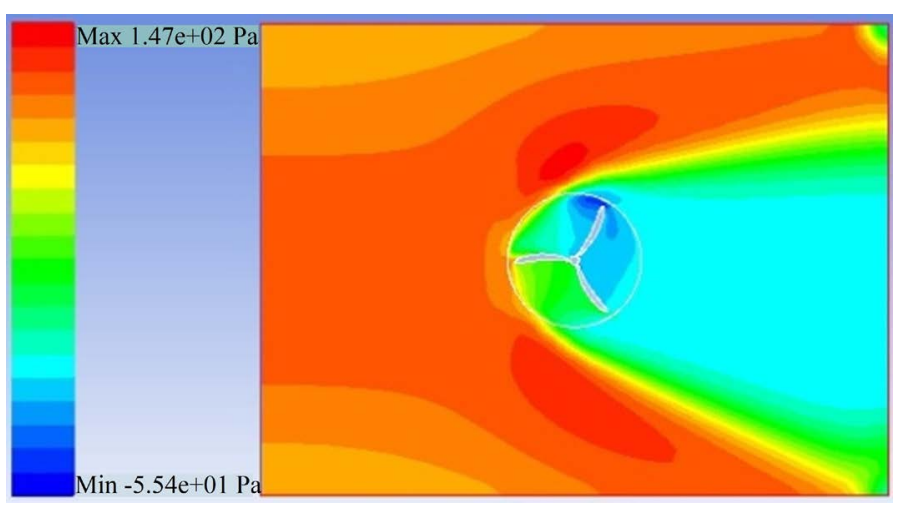

(c)

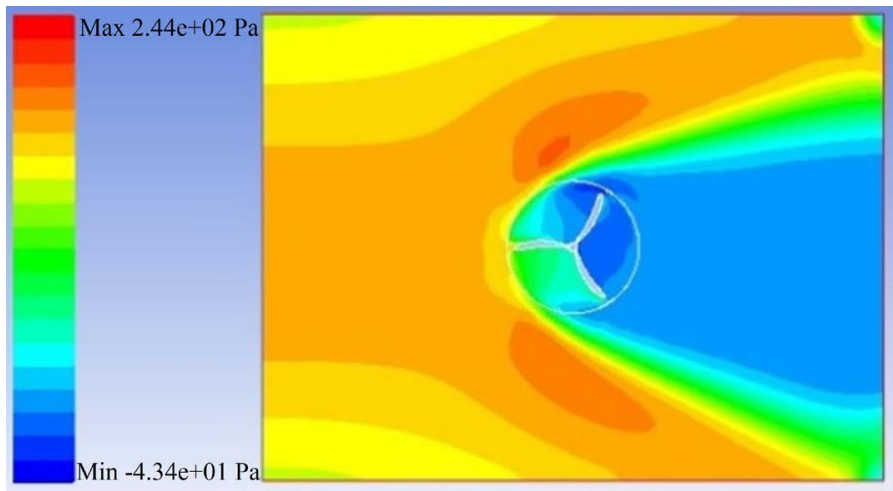

(d)

Figure 10. Pressure contour around NACA9510 model (three bladed) at TSR (a) 0.226, (b) 0.247 , (c) 0.271 and (d) 0.301 . 


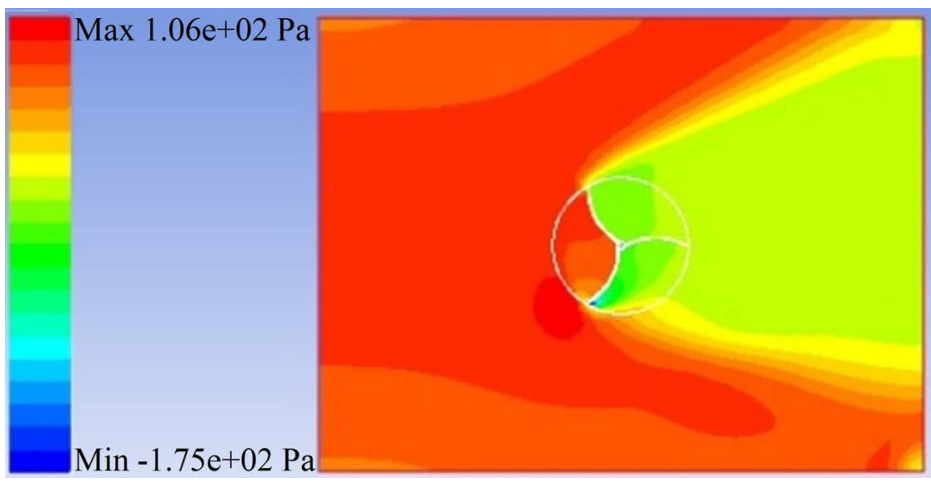

(a)

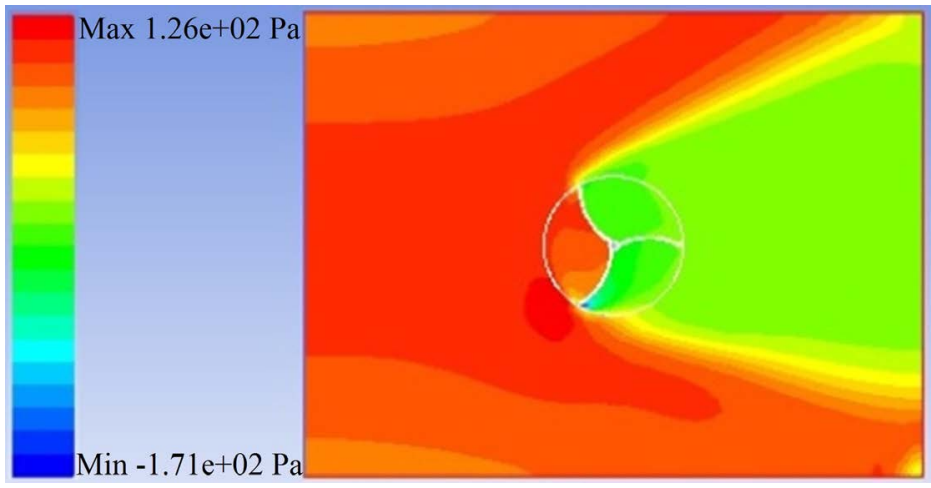

(b)

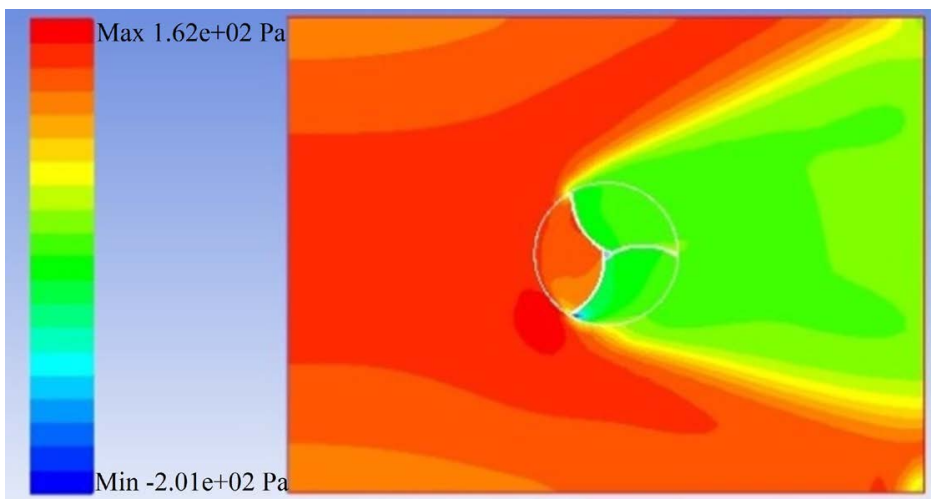

(c)

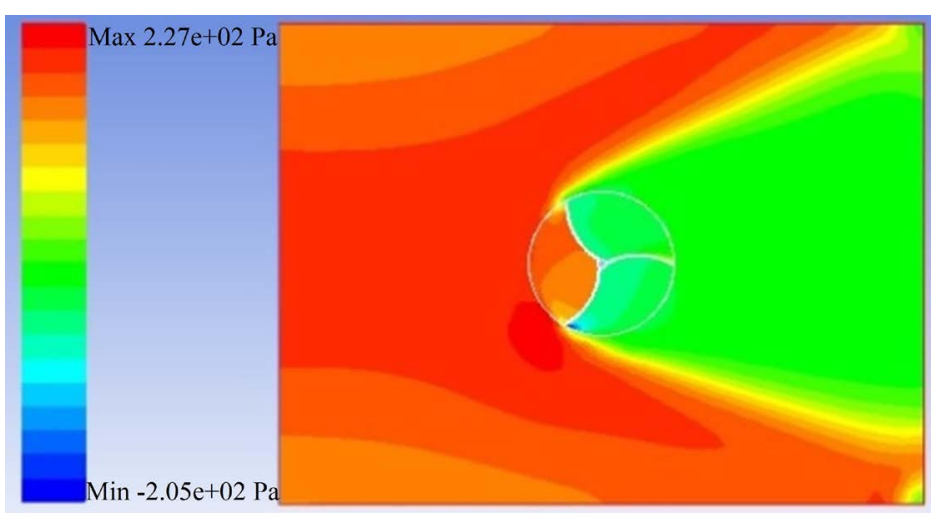

(d)

Figure 11. Pressure contour around quarter-circular model (three bladed) at TSR (a) 0.226 , (b) 0.247 , (c) 0.271 and (d) 0.301 . 


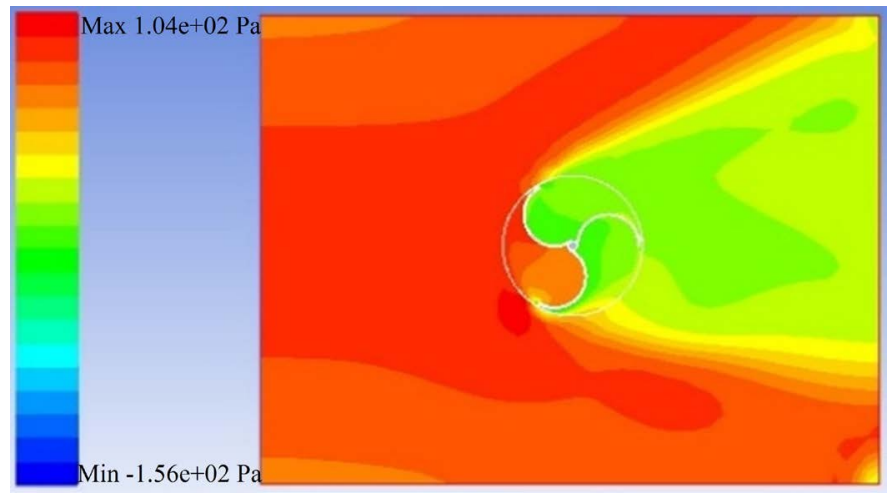

(a)

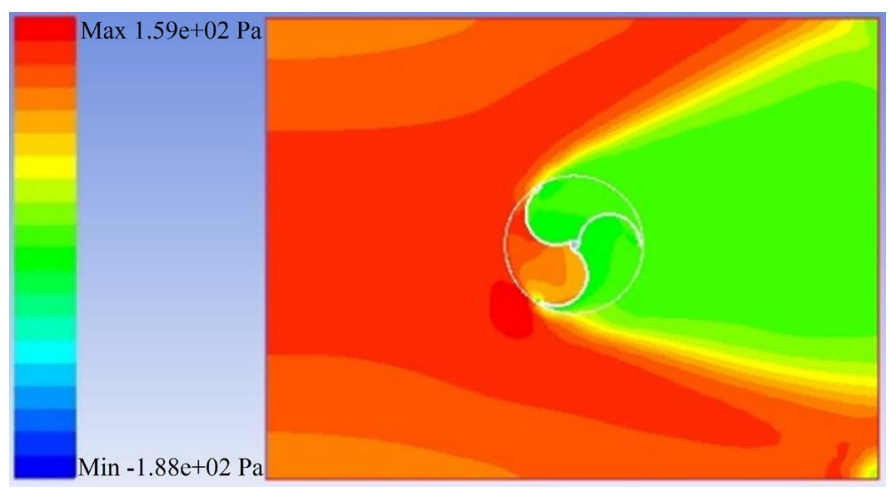

(b)

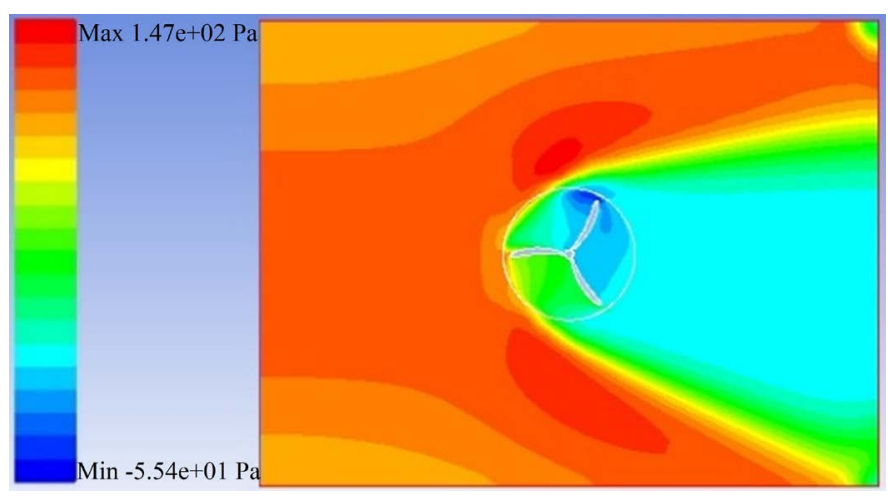

(c)

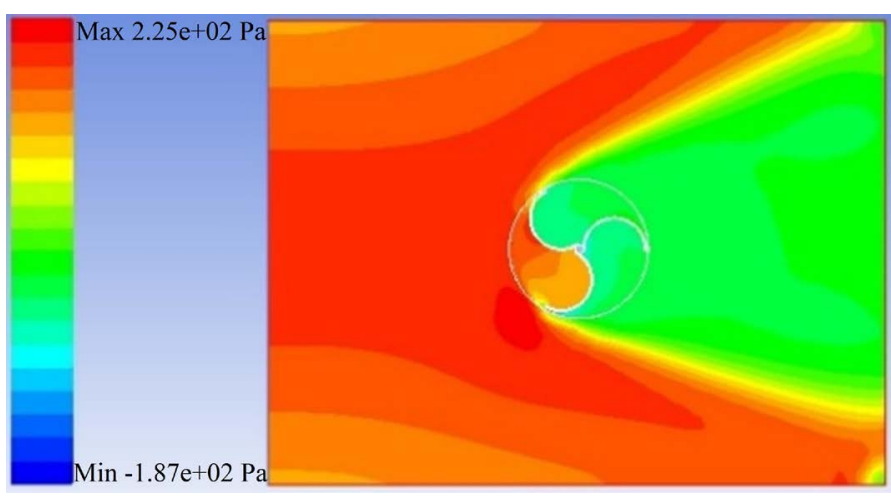

(d)

Figure 12. Pressure contour around semi-circular model (three bladed) at TSR (a) 0.226, (b) 0.247 , (c) 0.271 and (d) 0.301 . 
the convex sides (in the case of a circular blade) or between the negative camber and positive camber sides (in case of an aero-foil) are essential for the turbines to rotate. In general, it was observed that as the wind speed increases the pressures on the negative camber sides that are already negative, decrease further. For the aero-foil profiles of NACA 5510 and NACA 7510, pressure contours around the blades were shown in Figure 8 and Figure 9 respectively at different tip speed ratios. Between these two profiles, it was observed that the maximum pressures are lower and minimum pressures are higher in NACA 7510 than that of in NACA 5510.

The pressure contour around the NACA 9510 blade was shown in Figure 10 and was found to be very similar to that of NACA 7510 profile. Similarly, the pressure contour around the quarter-circular profile was shown in Figure 11 and it was found that the profiles were almost identical in all tip speed ratios. As well, the differential pressures between the opposite sides of the quarter-circular blade were smaller than the ones shown in the earlier contours for the NACA profiles shown above.

The pressure contours of the semi-circular blades as shown in Figure 12 have been found to be very similar to that of the quarter-circular ones except the differential pressures were a bit higher in the former ones than the latter ones.

The maximum and minimum pressures at different tip speed ratios were shown in Table 1 for different VAWT models.

It was observed in Table 1 that the differential pressure increases as the tip speed ratio increases in general. The differential pressures are comparatively higher in the circular rotors than the NACA ones. Among the NACA blades, the NACA 5510 has higher differential pressures than the other two blades.

\subsubsection{Velocity Contours}

The velocity contours with corresponding maximum and minimum values from the numerical simulation are presented in Figures 13-17 for all five models. In general, it is observed that the velocity starts decreasing when the wind approaches near a rotor and the velocity has been found to be the lowest at the trailing edge of a blade. However, the velocity of the flow stays relatively higher near the leading edge of the blades. Velocity drops significantly as the wind leaves the rotors.

Table 1. Maximum and minimum pressure after $5 \mathrm{sec}$. of rotation for all rotors at different TSR.

\begin{tabular}{ccccccccccc}
\hline & \multicolumn{2}{c}{ NACA5510 } & \multicolumn{2}{c}{ NACA7510 } & \multicolumn{2}{c}{ NACA9510 } & Semi-circular & \multicolumn{2}{c}{ Quarter-circular } \\
\cline { 2 - 11 } TSR & Max & Min & Max & Min & Max & Min & Max & Min & Max & Min \\
\cline { 2 - 11 } & & & \multicolumn{7}{c}{ Pascal } \\
\hline 0.226 & 107.7 & -135.3 & 93 & -96.4 & 97.1 & -96.4 & 104.4 & -159 & 105.8 & -174.1 \\
0.247 & 129.7 & -155.4 & 114.4 & -67.3 & 111.6 & -67.3 & 125 & -162 & 126.3 & -171.3 \\
0.271 & 163.9 & -145.6 & 145.1 & -46 & 146.6 & -46 & 159 & -188 & 162.2 & -200.9 \\
0.301 & 233.8 & -108.3 & 240.0 & -50 & 240.1 & -50 & 225.8 & -186.6 & 226.9 & -205.4 \\
\hline
\end{tabular}




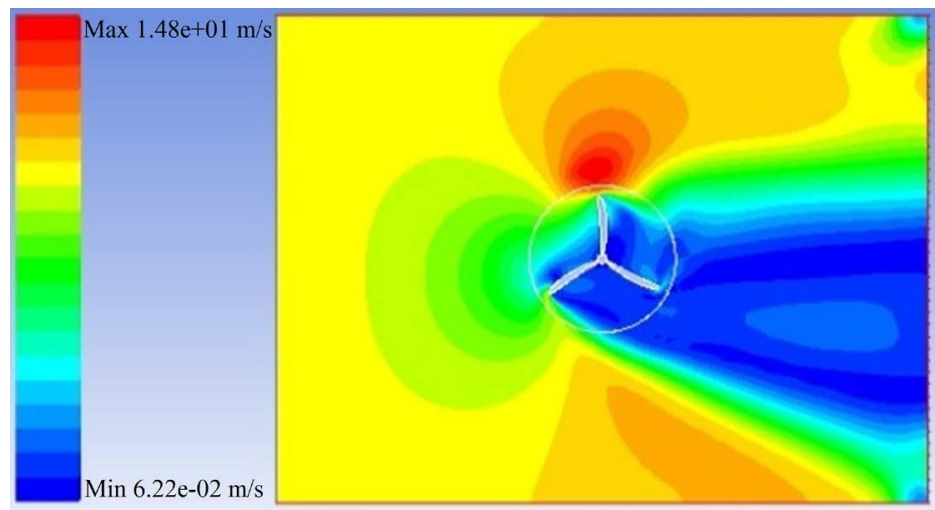

(a)

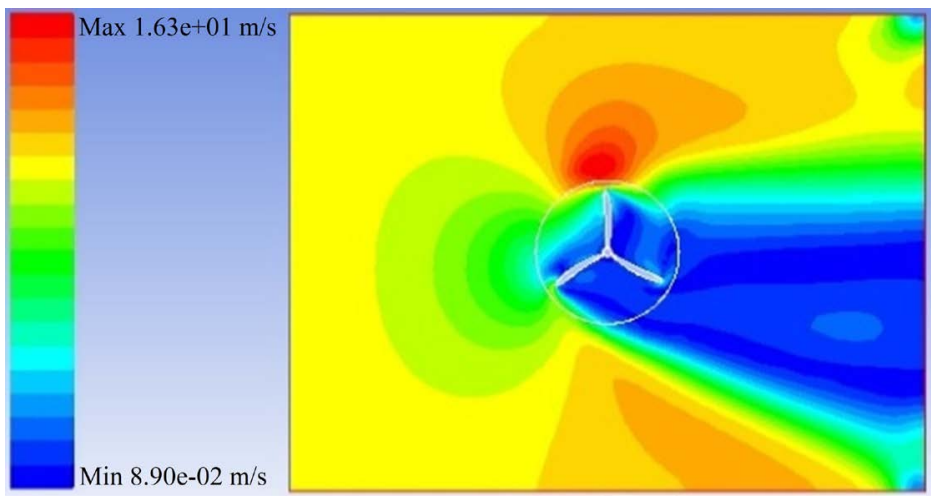

(b)

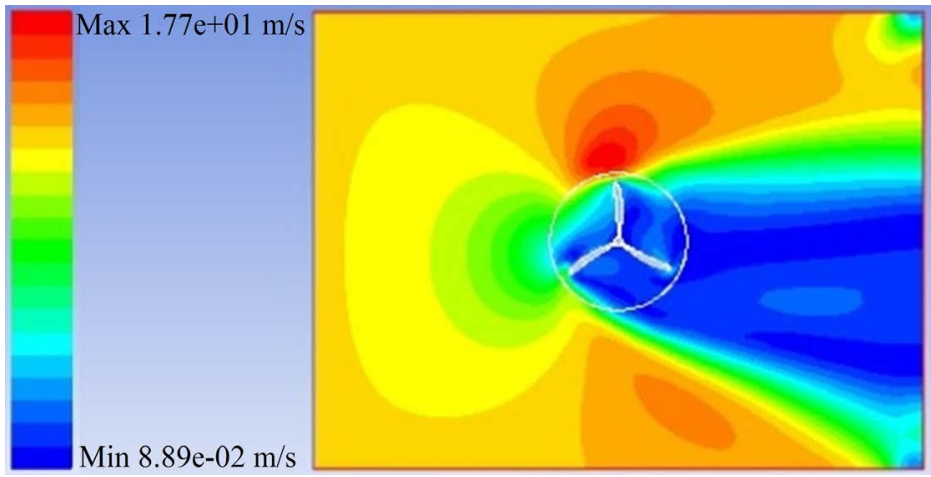

(c)

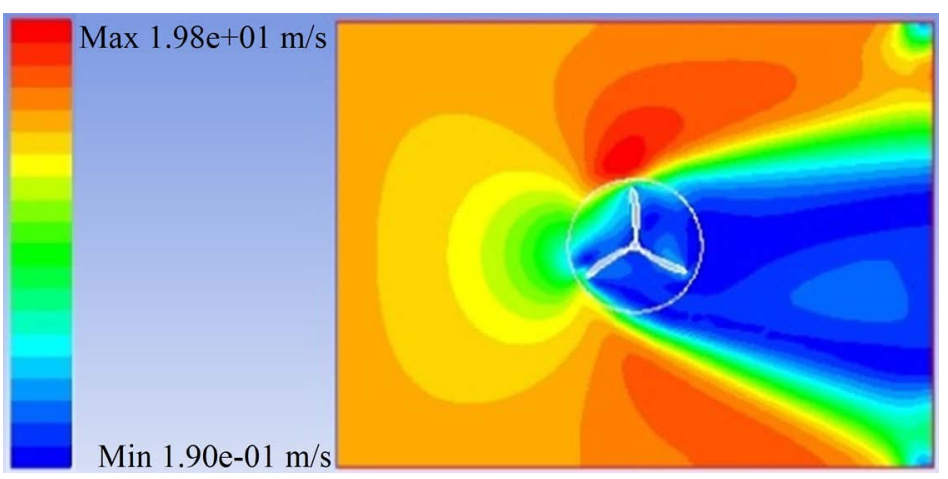

(d)

Figure 13. Velocity contour around NACA5510 model (three bladed) at TSR (a) 0.226, (b) 0.247 , (c) 0.271 and (d) 0.301 . 


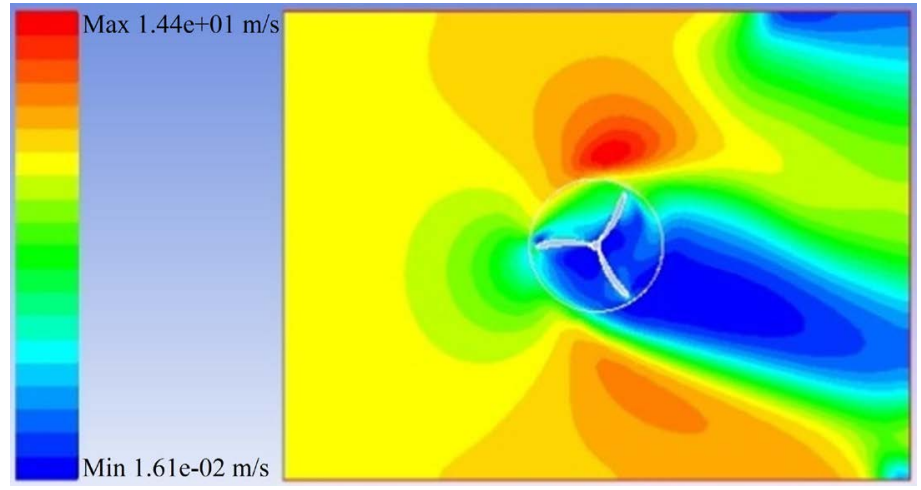

(a)

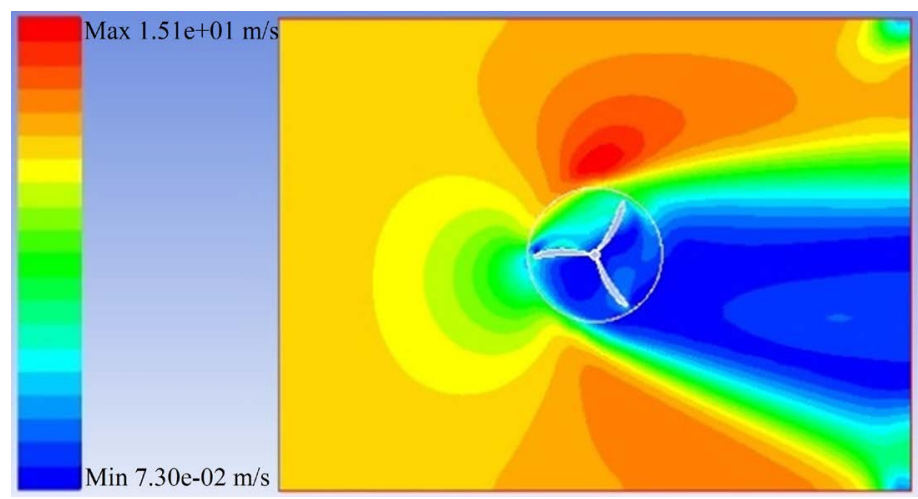

(b)

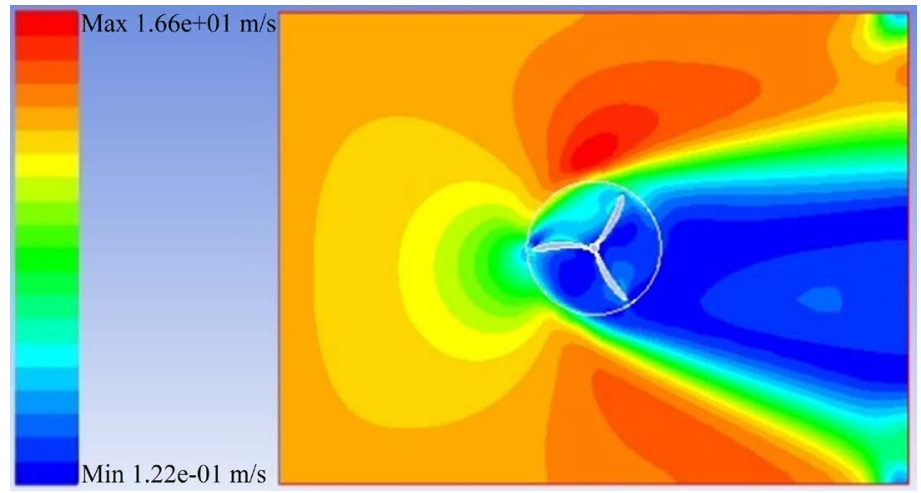

(c)

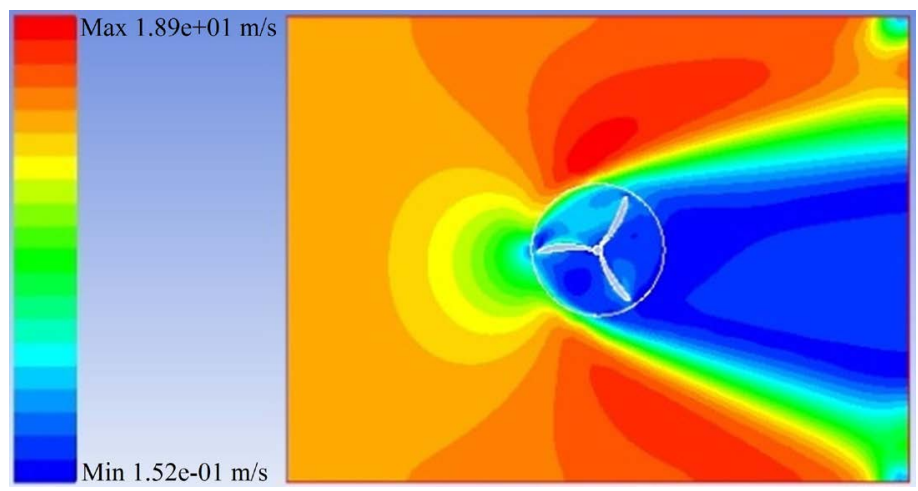

(d)

Figure 14. Velocity contour around NACA7510 model (three bladed) at TSR (a) 0.226, (b) 0.247 , (c) 0.271 and (d) 0.301 . 


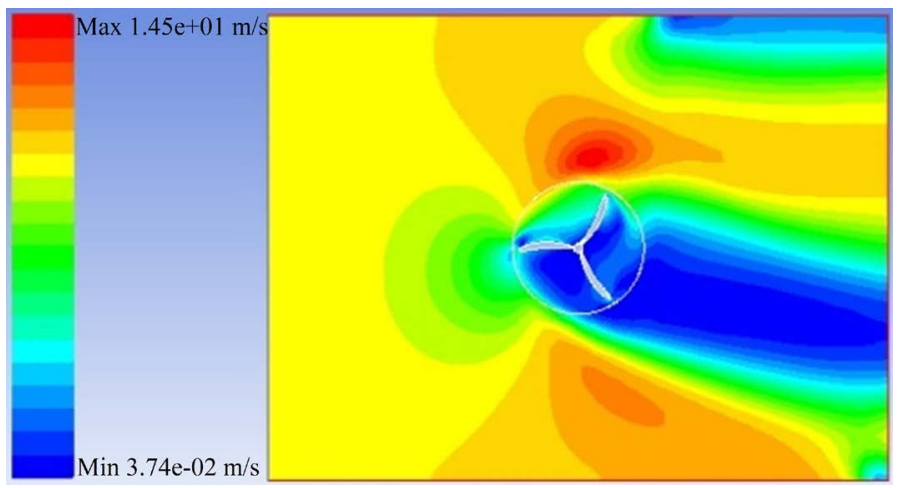

(a)

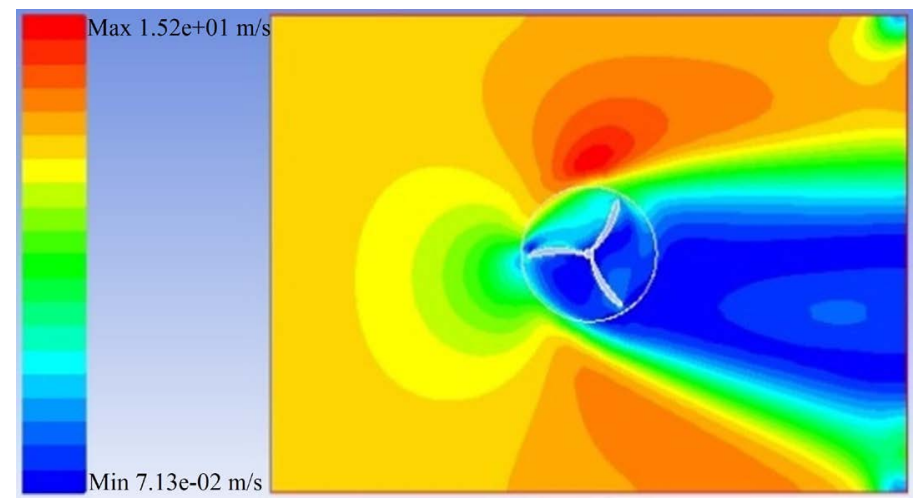

(b)

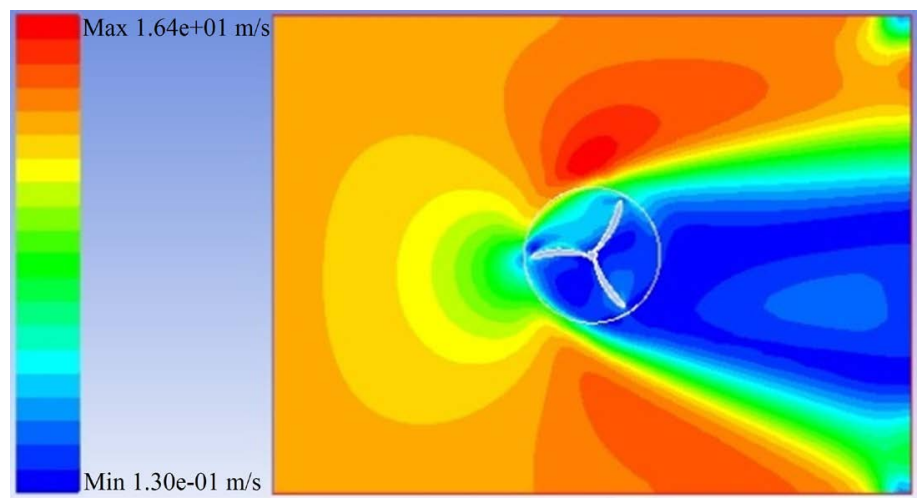

(c)

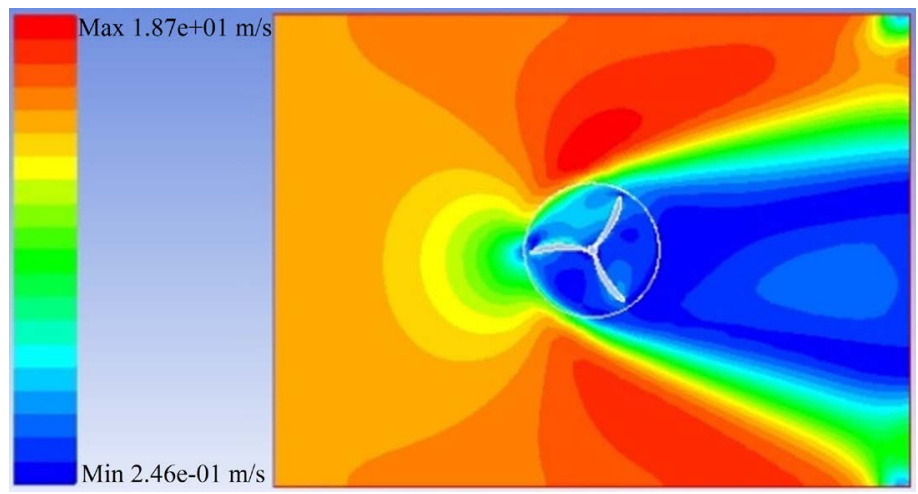

(d)

Figure 15. Velocity contour around NACA9510 model (three bladed) at TSR (a) 0.226, (b) 0.247 , (c) 0.271 and (d) 0.301 . 


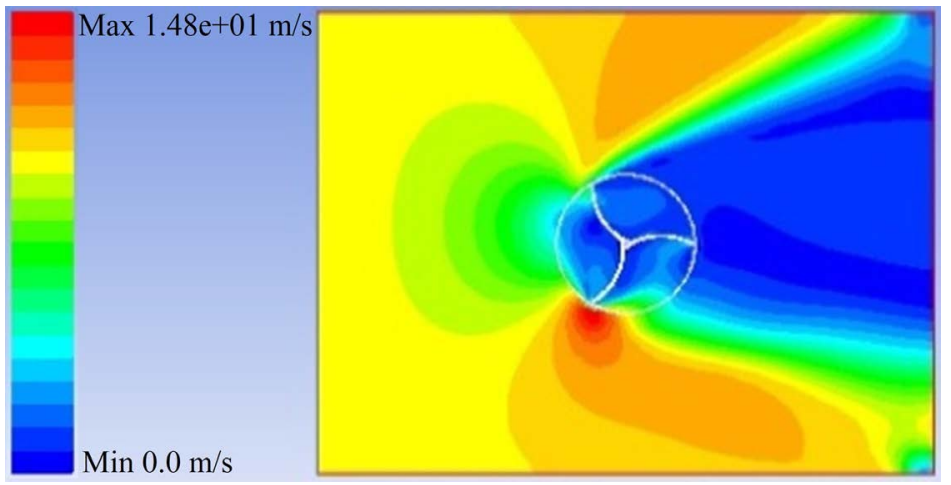

(a)

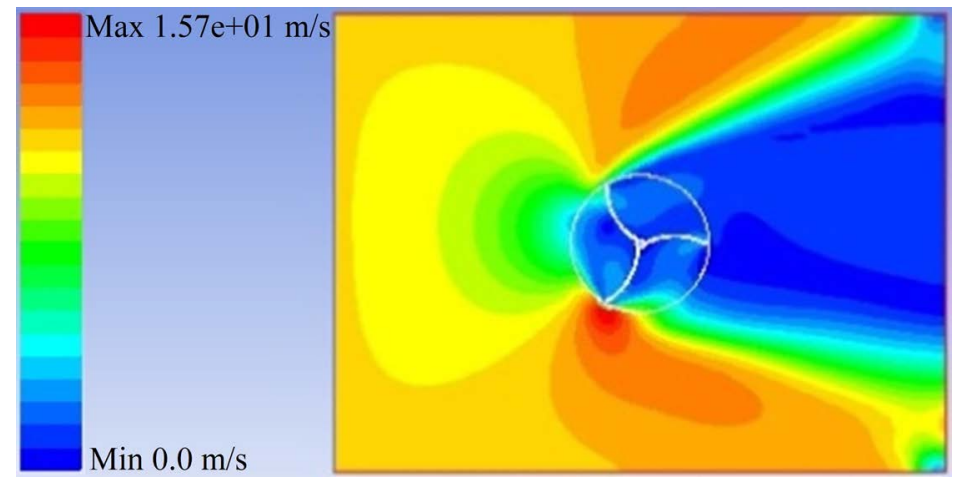

(b)

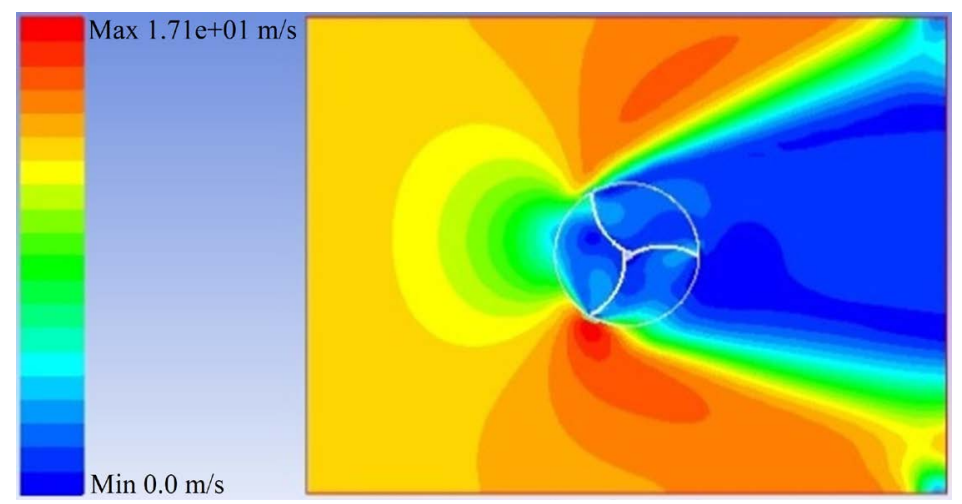

(c)

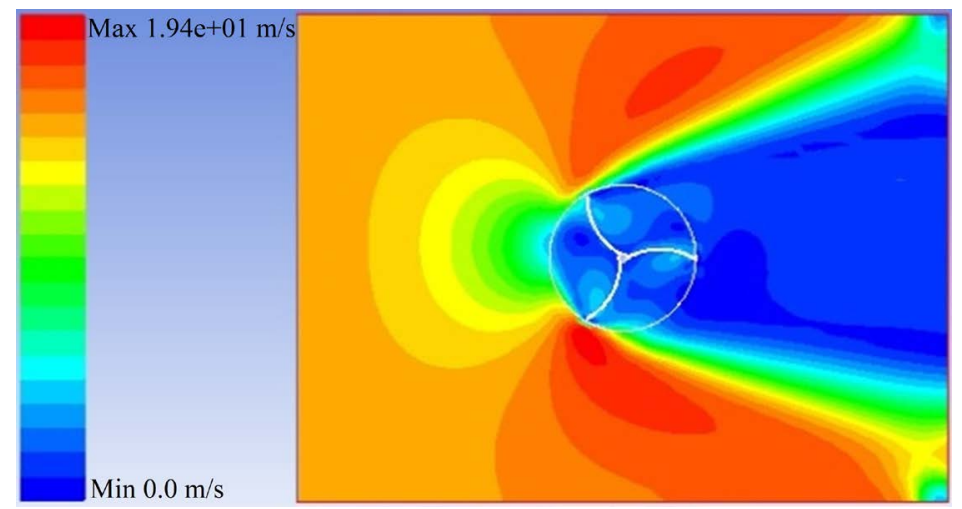

(d)

Figure 16. Velocity contour around quarter-circular model (three bladed) at TSR (a) 0.226, (b) 0.247 , (c) 0.271 and (d) 0.301 . 


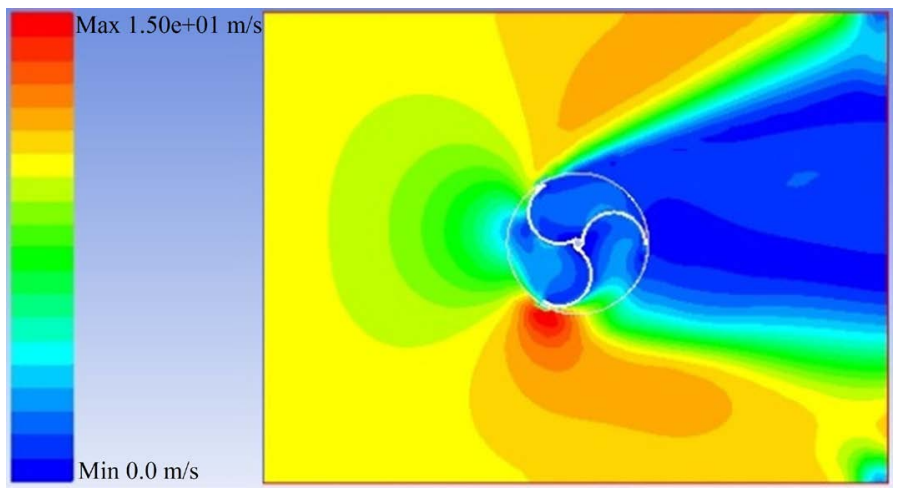

(a)

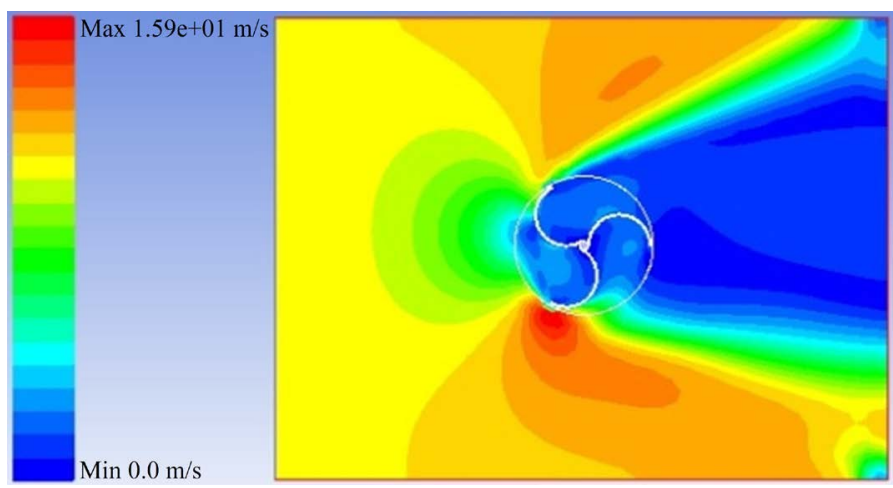

(b)

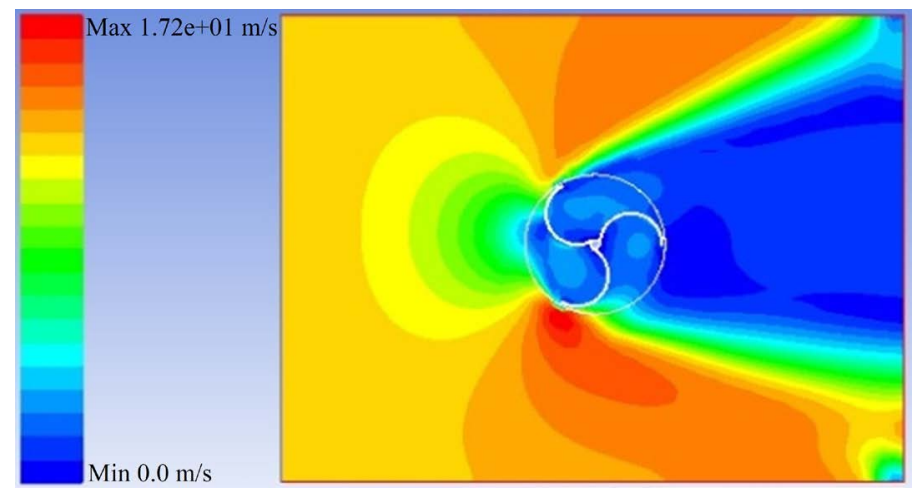

(c)

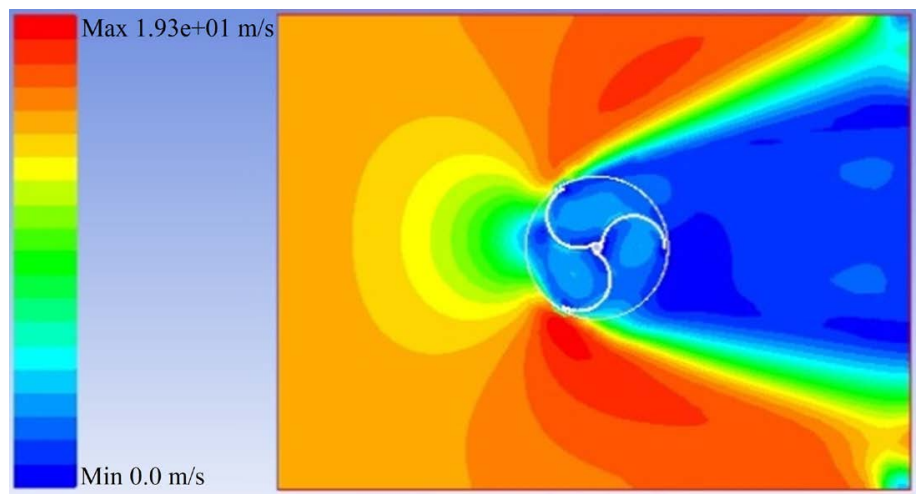

(d)

Figure 17. Velocity contour around semi-circular model (three bladed) at TSR (a) 0.226, (b) 0.247 , (c) 0.271 and (d) 0.301 . 
Table 2 shows the maximum and minimum velocities of all models at $t=5$ seconds. The maximum and minimum velocity patterns at a given tip speed ratio for all models are somewhat identical. As the free stream velocities increase, the maximum velocities for all cases increase as well. Unlike the NACA blades, both quarter-circular and semi-circular blades have zero velocities at the rotor exits.

\subsubsection{Drag Coefficient $\left(\mathrm{C}_{\mathrm{d}}\right)$}

As the rotation angle of a rotor changes with time, so does the drag coefficient $\left(C_{d}\right)$. As the angle of rotation for a given rotor increases the drag coefficient also increases and reaches to a peak value and then starts decreasing again as the rotor angle continuously increases making a sinusoidal pattern. This drag coefficient is the primary factor in producing the necessary torque that causes the rotor to turn and to produce power.

\section{Drag coefficient vs. Angle of Rotation}

Figure 18 shows the drag coefficient vs. rotor angle plots for different VAWT models with a rotor angle interval of $15^{\circ}$ and plotted between $0^{\circ}$ and $360^{\circ}$. As observed in the figure, all plots have oscillatory sinusoidal type patterns.

It is observed in Figure 19 that the semi-circular blade produces the least oscillatory drag coefficient plot, where the quarter-circular one produces the most oscillatory plot among the other models.

Figure 20 shows the average drag coefficient against the tip speed ratio for all models. The highest coefficient has been found in NACA blade with the high camber number i.e. in NACA 5510. It is also observed that drag coefficient increases with tip speed ratio for all models in general.

\subsubsection{Lift Coefficient $\left(C_{l}\right)$}

For the aero-foil based VAWTs, the lift coefficients are also as important as the drag coefficients. Lift forces are responsible for producing negative pressures on the aero-foils that increase the drag force in general.

\section{Lift coefficient vs. Angle of Rotation}

The lift coefficients against the angle of rotation from $0^{\circ}$ to $360^{\circ}$ for all models

Table 2. Maximum and minimum velocities after $5 \mathrm{sec}$. of rotation for all rotors at different TSR.

\begin{tabular}{|c|c|c|c|c|c|c|c|c|c|c|}
\hline \multirow{3}{*}{ TSR } & \multicolumn{2}{|c|}{ NACA5510 } & \multicolumn{2}{|c|}{ NACA7510 } & \multicolumn{2}{|c|}{ NACA9510 } & \multicolumn{2}{|c|}{ Semi-circular } & \multicolumn{2}{|c|}{ Quarter-circular } \\
\hline & $\operatorname{Max}$ & Min & Max & Min & Max & Min & Max & Min & Max & Min \\
\hline & \multicolumn{10}{|c|}{$\mathrm{m} / \mathrm{s}$} \\
\hline 0.226 & 14.85 & 0.05 & 14.4 & 0.02 & 14.5 & 0.04 & 15.01 & 0 & 14.85 & 0 \\
\hline 0.247 & 16.3 & 0.09 & 15.1 & 0.07 & 15.2 & 0.07 & 15.9 & 0 & 15.7 & 0 \\
\hline 0.271 & 17.7 & 0.09 & 16.5 & 0.12 & 16.4 & 0.13 & 17.2 & 0 & 17.06 & 0 \\
\hline 0.301 & 19.8 & 0.19 & 18.9 & 0.15 & 18.7 & 0.25 & 19.3 & 0 & 19.4 & 0 \\
\hline
\end{tabular}




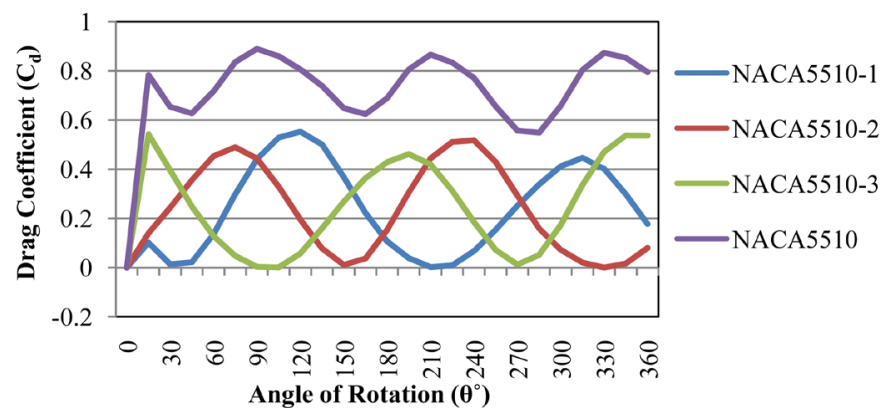

(a)

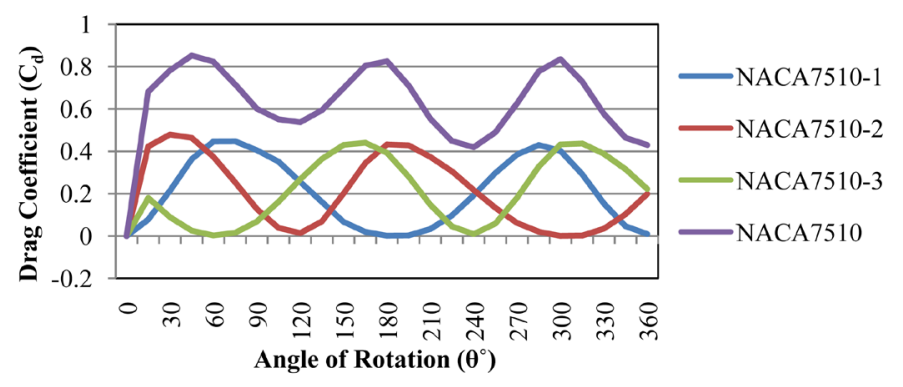

(b)

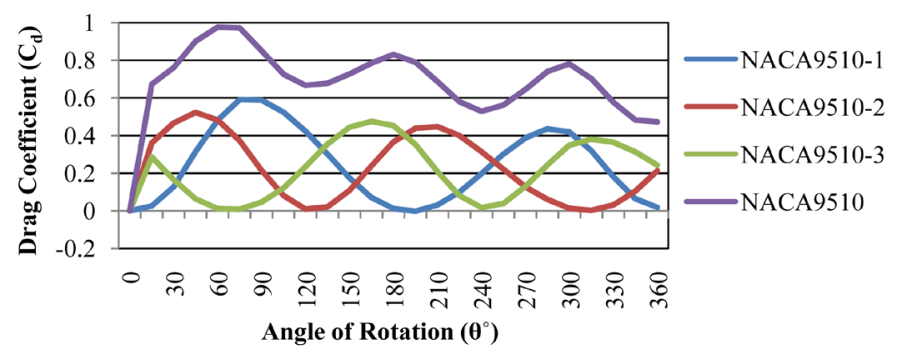

(c)

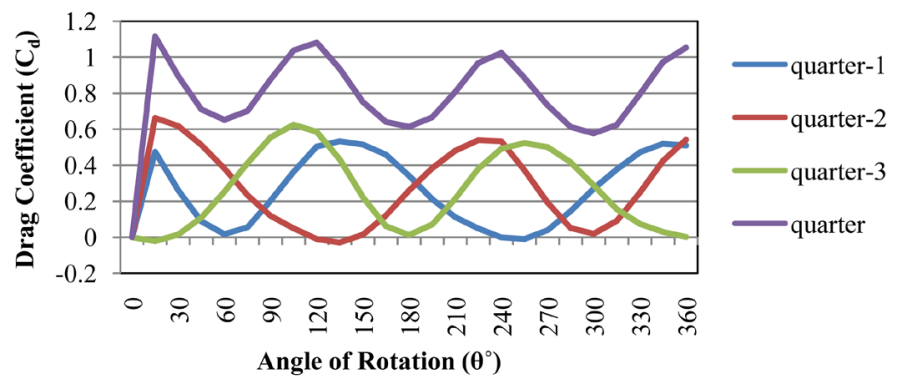

(d)

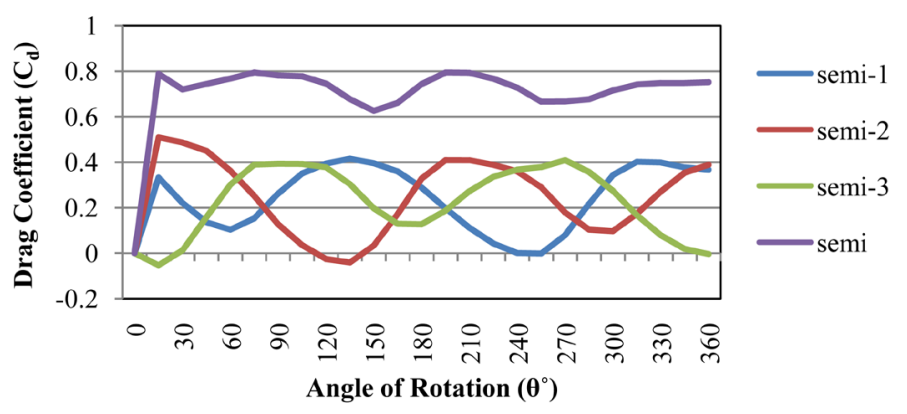

(e)

Figure 18. Drag coefficient $\left(C_{d}\right)$ vs. angle of rotation $(\theta)$ for single bladed effect and three bladed-combined effects at TSR 0.226 for five models. 


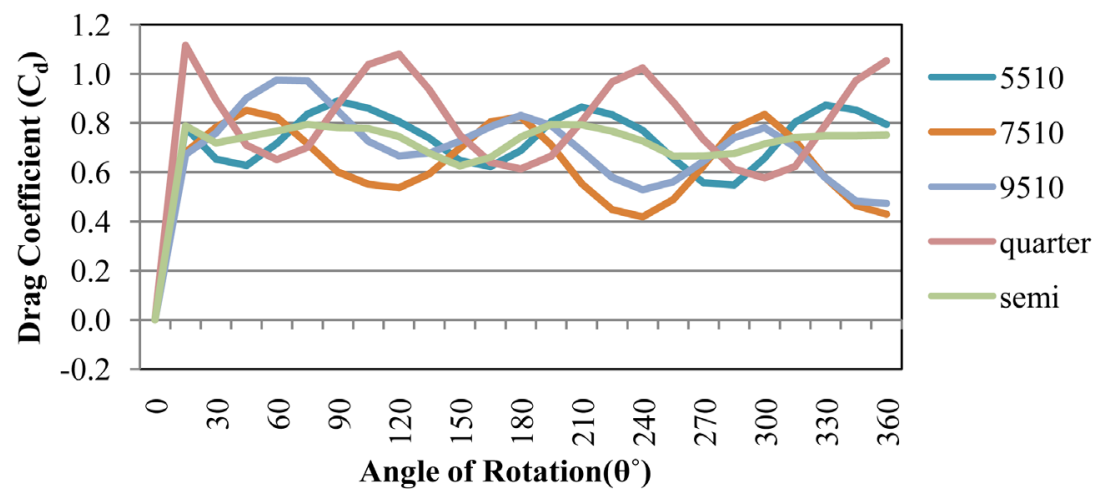

Figure 19. Drag coefficient $\left(C_{d}\right)$ vs. angle of rotation $(\theta)$ for three bladed combined effects at TSR 0.226 for five models.

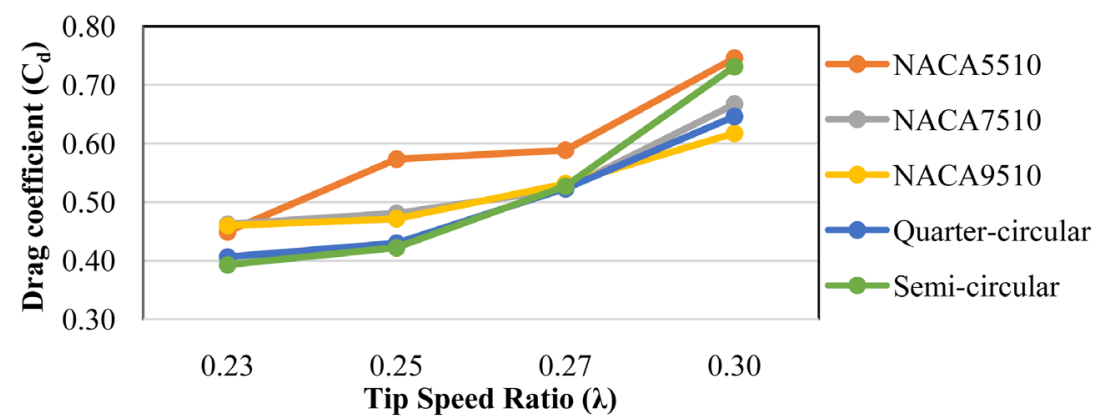

Figure 20. Average drag coefficient $\left(C_{d}\right)$ vs. tip speed ratio $(\lambda)$ for five different models (three bladed).

are shown in Figure 21. The combined (all three blades for a given rotor) lift coefficients against the angle of rotation for all models are compared with each other in Figure 22. It is observed that the semicircular model shows very low oscillation as compared to the other models. On the contrary, the quartercircular model and the NACA 7510 model have relatively higher drag coefficients as compared to the others.

Figure 23 shows the lift coefficients against the tip speed ratio for all five models. It is observed that the lift coefficient increases as the tip speed ratio increases in general and NACA 7510 model produces the best coefficient among all models. However, for the semi-circular one the lift coefficient is higher than the rest of the models and starts decreasing as the tip speed ratio increases.

\subsubsection{Torque Coefficient $\left(\mathrm{C}_{\mathrm{q}}\right)$}

At a given rotational angle, the torque has been calculated based on the numerical simulation data. However, as it always changes with the rotational angle, a combined blade effect (torque Coefficient) was averaged for a steady flow of wind across a given VAWT model.

\section{Torque Coefficient vs. Angle of Rotation}

In Figure 24, the torque coefficients of different models for single blades as well as for combined blades were plotted against the angle of rotation in an interval of $0^{\circ}$ to $360^{\circ}$. The single bladed plots are highly oscillatory and similar in 


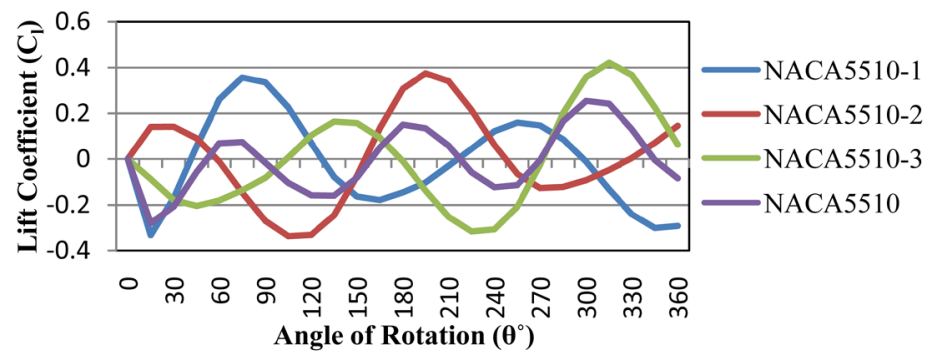

(a)

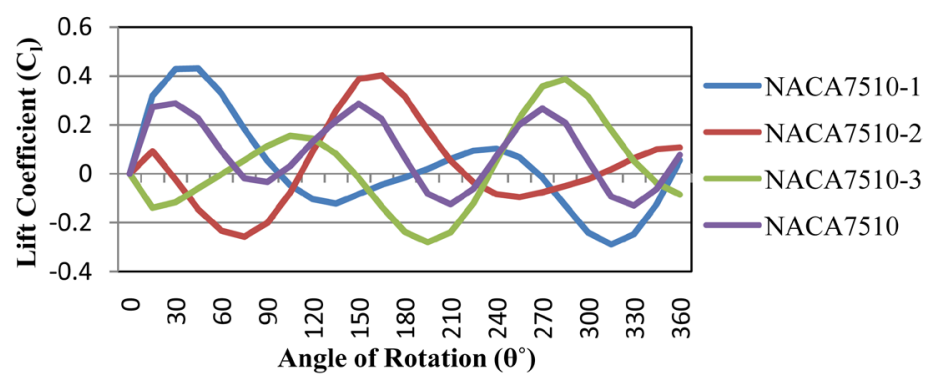

(b)

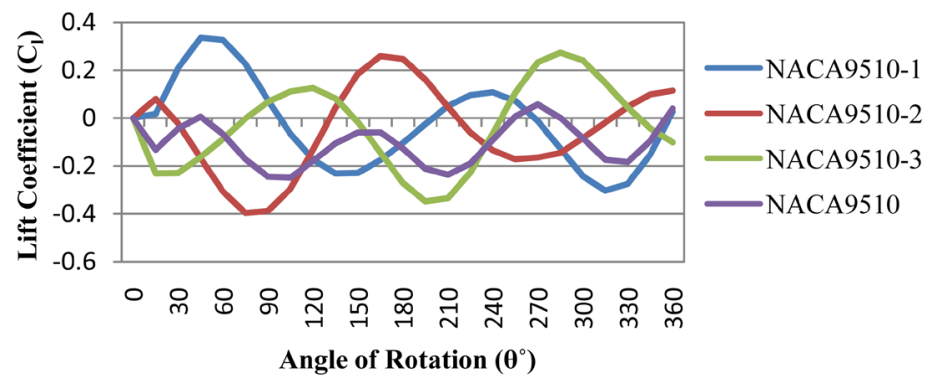

(c)

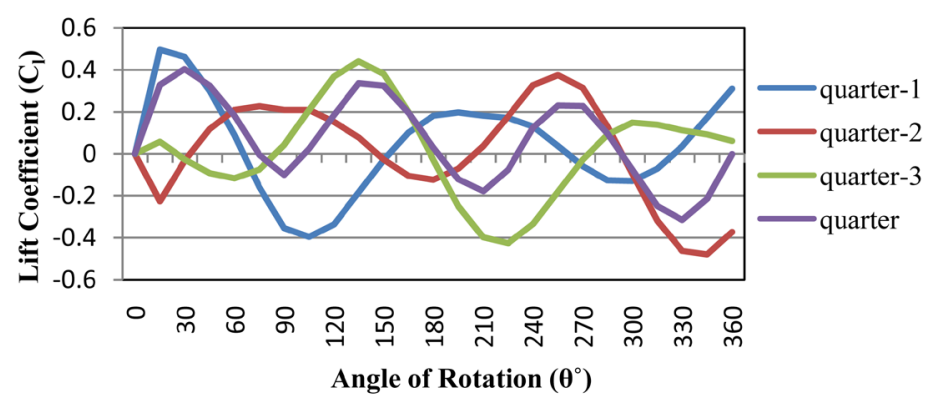

(d)

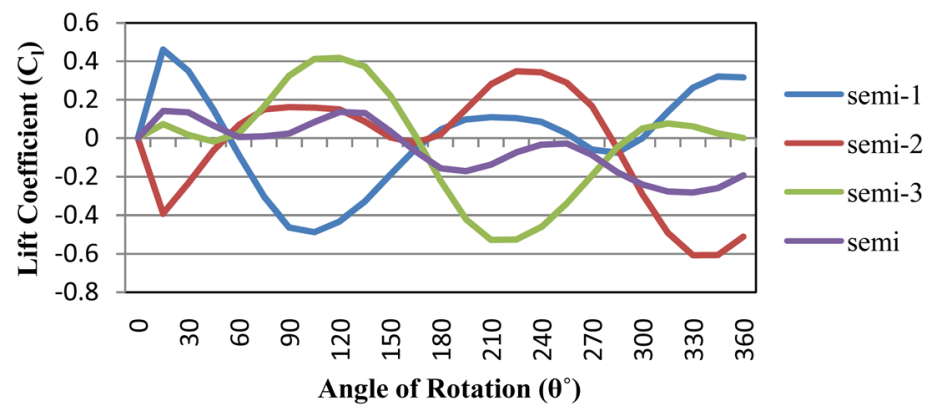

(e)

Figure 21. Lift coefficient $\left(C_{l}\right)$ vs. angle of rotation $(\theta)$ for single bladed and three bladed combined effects at TSR 0.226 for five models. 


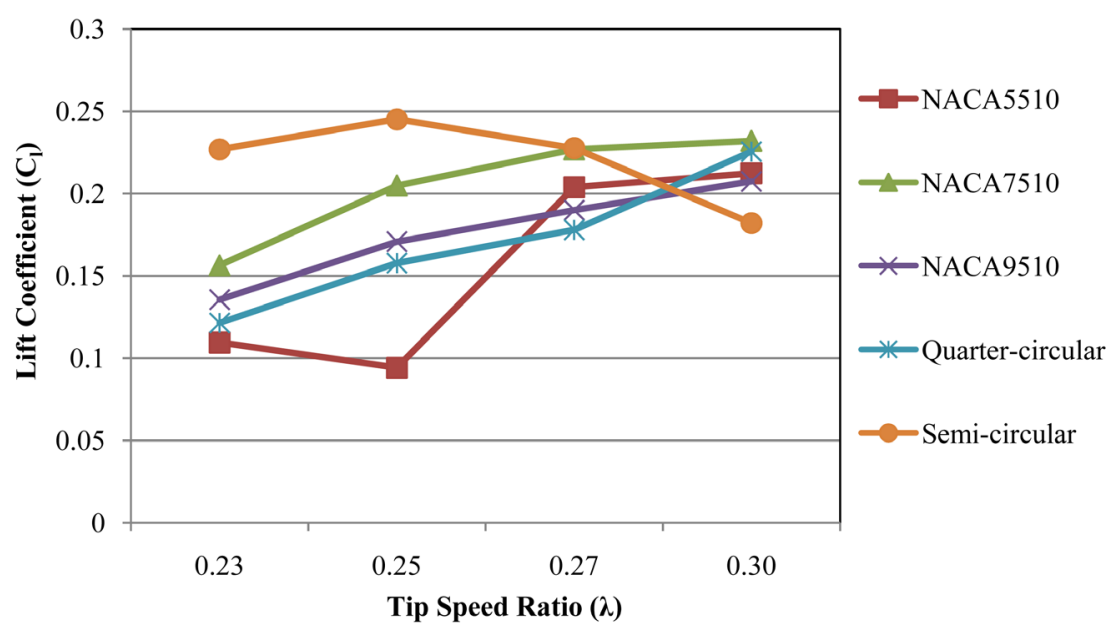

Figure 22. Lift coefficient $\left(C_{l}\right)$ vs. angle of rotation $(\theta)$ for three bladed combined effects at TSR 0.226 for five models.

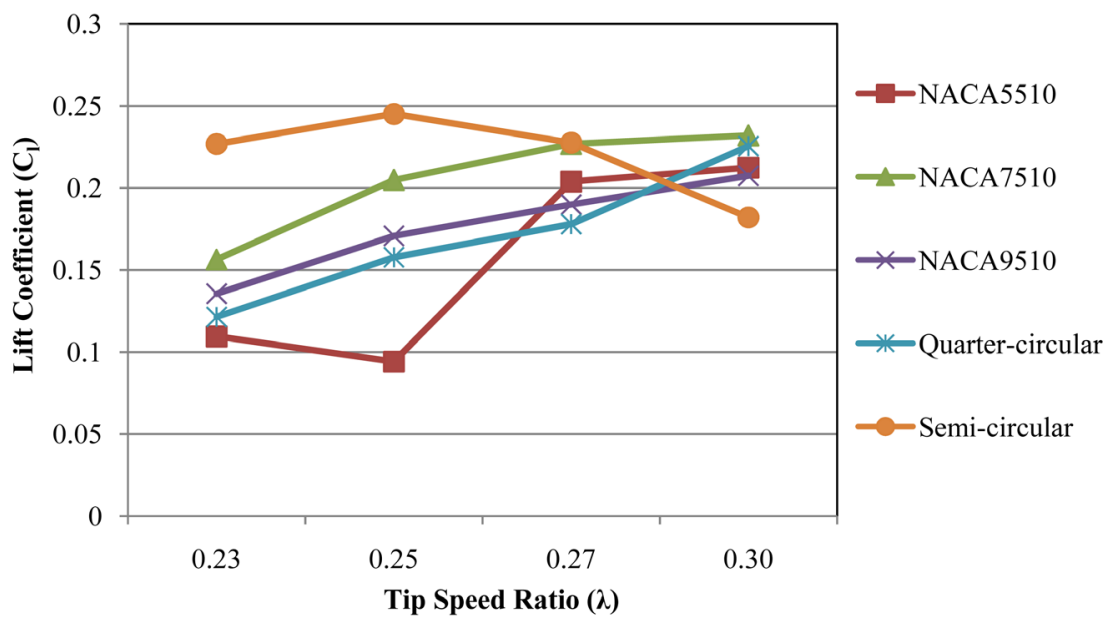

Figure 23. Average lift coefficient $\left(C_{l}\right)$ vs. tip speed ratio $(\lambda)$ for five different three bladed models.

pattern with picks being separated by roughly $120^{\circ}$. The combined ones are much smaller in magnitude as compared to the single bladed ones.

The three bladed combined torque coefficients for all models were shown in Figure 25. The highest and the lowest torque coefficients have been found for the semi-circular model and the NACA 9510 model respectively.

Torque coefficients based on the model geometries and the corresponding torques have been plotted against the tip speed ratio in Figure 26. On the other hand, Figure 27 shows the distribution of torque coefficient based on the numerical simulation only. The highest torque coefficient has been found for NACA 5510 model at a given tip speed ratio as shown in both figures. On the contrary, the same two figures show that the lowest coefficient has been yielded for the semi-circular one. It was found that around a tip speed ratio of 0.25 both semi-circular and quarter-circular models have the lowest torque coefficients. Furthermore, it is observed that all three NACA models yielded higher torque coefficients at a given tip speed ratio than the circular ones. 


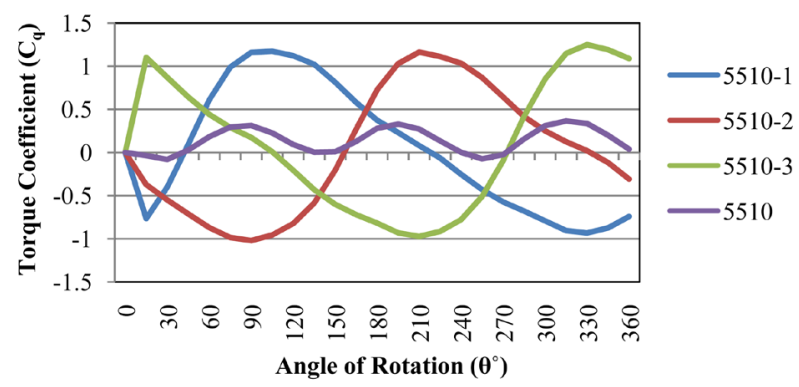

(a)

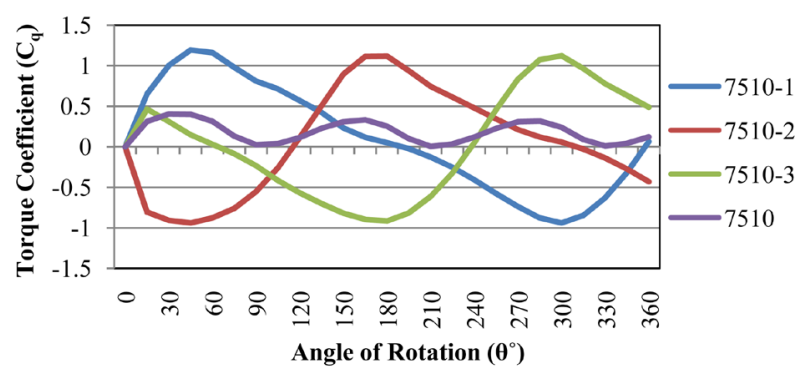

(b)

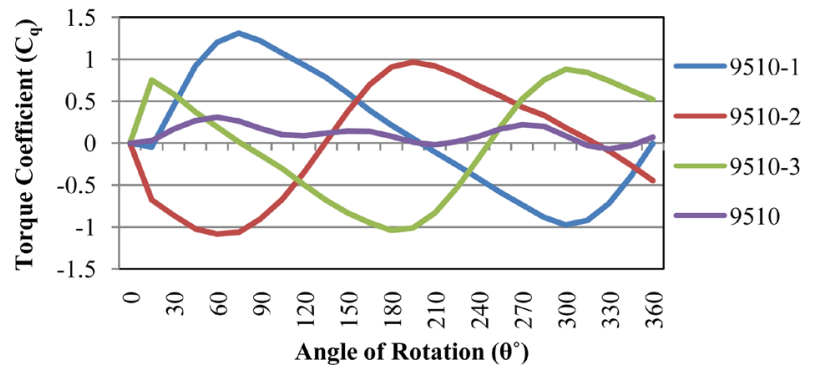

(c)

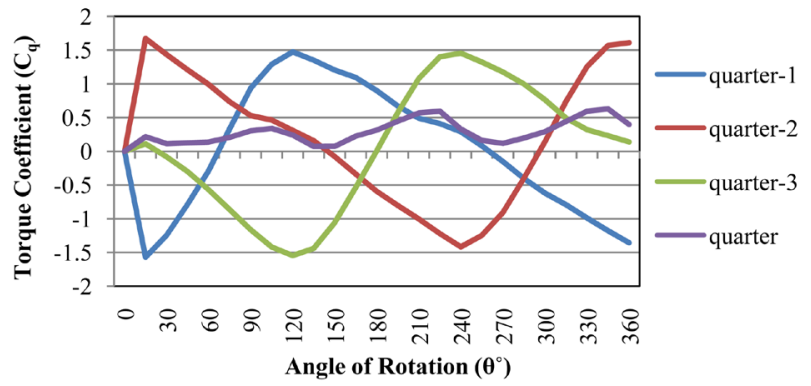

(d)

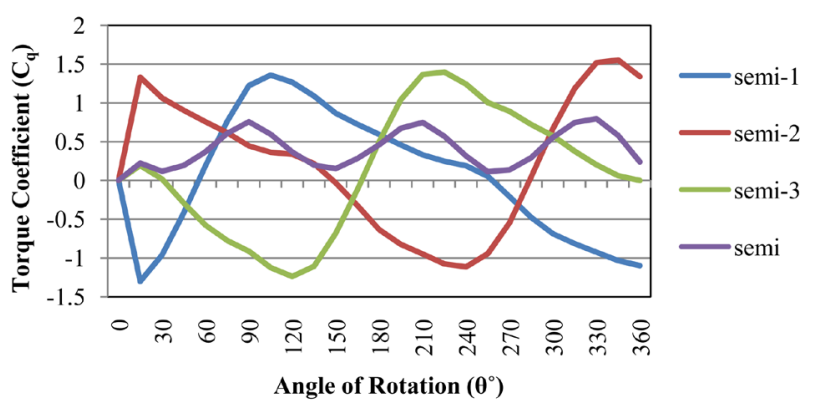

(e)

Figure 24. Torque coefficient $\left(C_{q}\right)$ vs. angle of rotation $(\theta)$ for single bladed and three bladed-combined effect at TSR 0.226 for five models. 


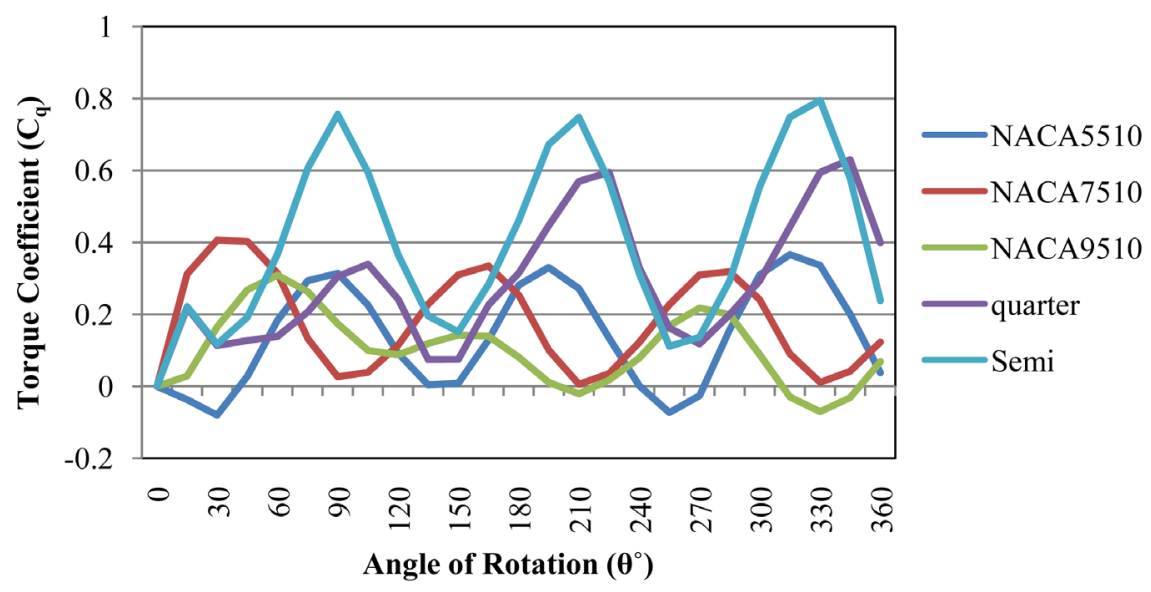

Figure 25. Torque coefficient $\left(C_{q}\right)$ vs. angle of rotation $(\theta)$ for three bladed combined effect at TSR 0.226 for five models.

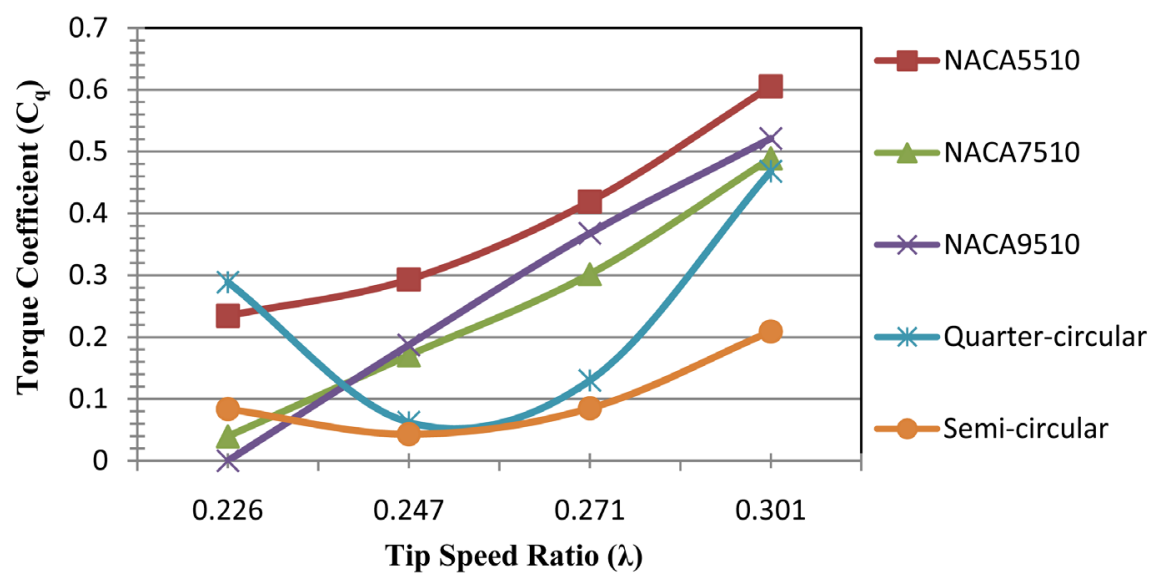

Figure 26. Calculated torque coefficient $\left(C_{q}\right)$ vs. tip speed ratio $(\lambda)$ for five different three bladed models at $t=5 \mathrm{sec}$.

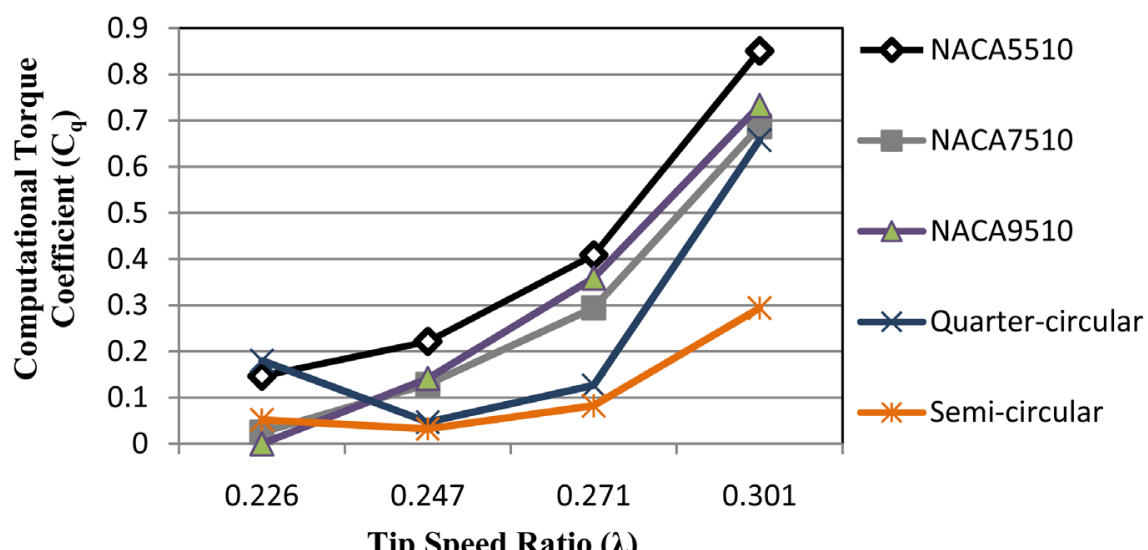

Figure 27. Computational torque coefficient $\left(C_{q}\right)$ vs. tip speed ratio $(\lambda)$ for five different three bladed models at $t=5 \mathrm{sec}$.

\subsubsection{Power Coefficient}

Figure 28 shows the power coefficients of different VAWT models against the tip speed ratio based on the geometries and the corresponding powers; where 


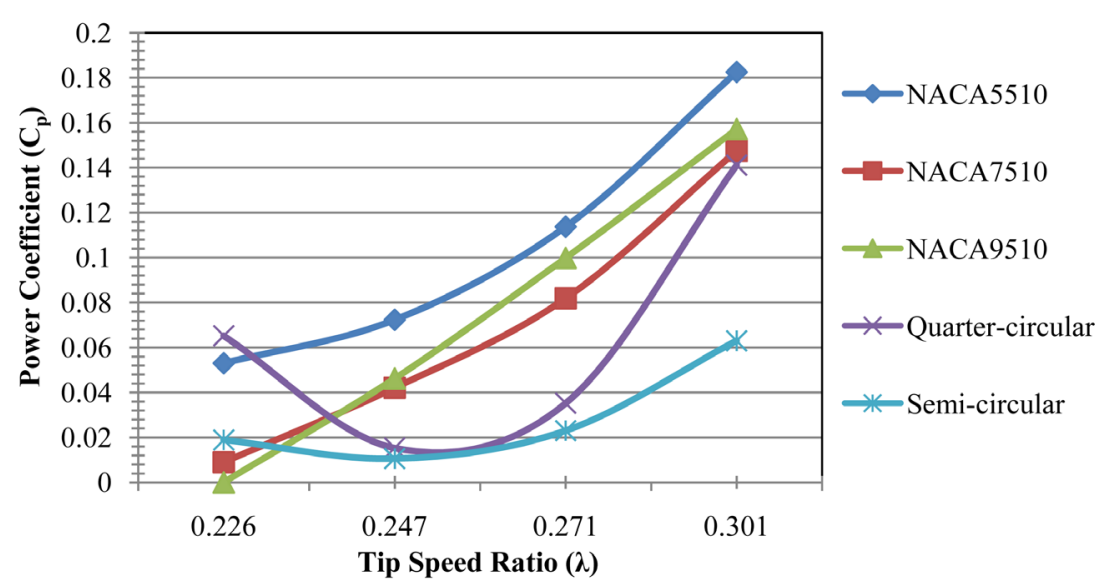

Figure 28. Calculated power coefficient $\left(C_{p}\right)$ vs. tip speed ratio $(\lambda)$ for five different three bladed models at $t=5 \mathrm{sec}$.

Figure 29 shows the distribution of power coefficients based on the numerical simulation directly. The power coefficient increases as the tip speed ratio increases in general. The highest coefficient was observed for NACA 5510 at a given tip speed ratio as shown in Figure 28, where the smallest coefficient was observed for the semicircular one. For the circular ones (semi-circular and quarter-circular), at approximately a tip speed ratio of 0.26 the torque coefficients are the lowest and they start increasing passed this value.

\subsection{Experimental Results}

For experimental investigation, three physical models NACA5510, NACA7510, and the semicircular were fabricated and tested at three different wind speeds.

\subsubsection{Torque Coefficient}

The experimental torque coefficients have been found to be quite different from the numerical ones as can be seen in Figure 30.

NACA 5510 model has the lowest torque coefficient among all. Below a tip speed ratio of 0.32 , the semi-circular model has a higher torque coefficient as compared to the other two; however, passed 0.32 the coefficient for the semicircular one starts decreasing. Where the coefficient for NACA 7510 keeps increasing even passed this point.

\subsubsection{Power Coefficient}

The experimental power coefficient plot as shown in Figure 31 is very similar to the torque coefficient plot shown before. At a low tip speed ratio the semi-circular model has the highest power coefficient; on the other hand at a higher tip speed ratio (above 0.32) NACA 7510 has the highest coefficient among all. NACA 5510 model has the lowest coefficient at a given tip speed ratio.

\subsection{Comparison of Numerical and Experimental Coefficients}

Both numerical and experimental power coefficients against the tip speed ratio were shown in Figure 32. NACA 7510 shows good power coefficients both 


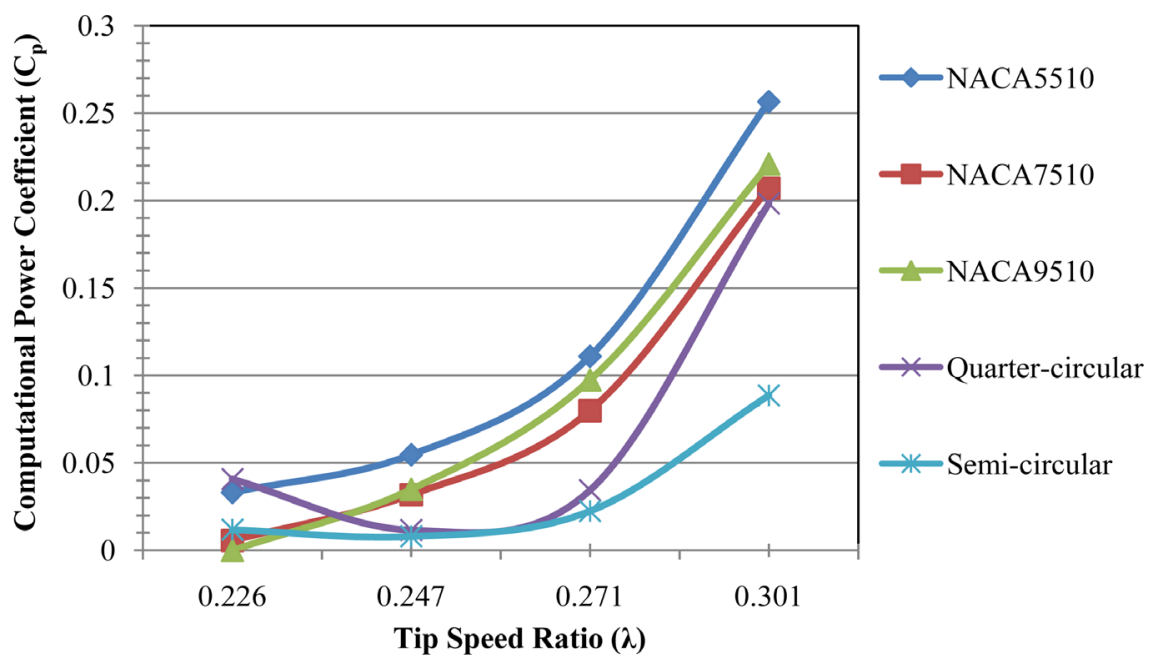

Figure 29. Computational power coefficient $\left(C_{p}\right)$ vs. tip speed ratio $(\lambda)$ for five different three bladed models at $t=5 \mathrm{sec}$.

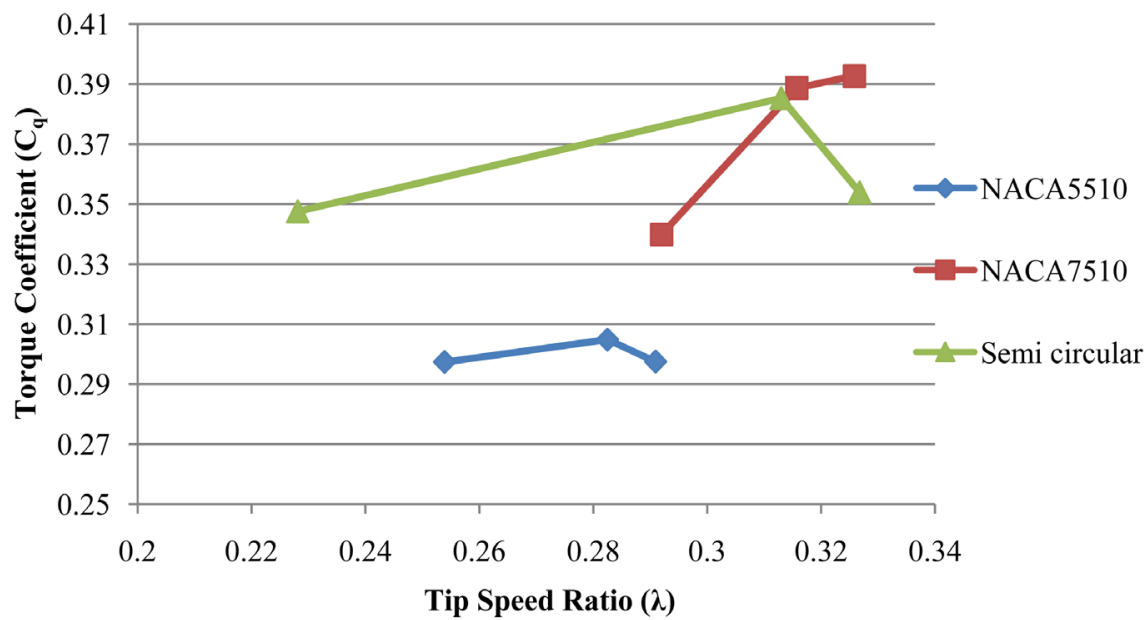

Figure 30. Experimental torque coefficient $\left(C_{q}\right)$ vs. tip speed ratio $(\lambda)$ for three different three bladed models.

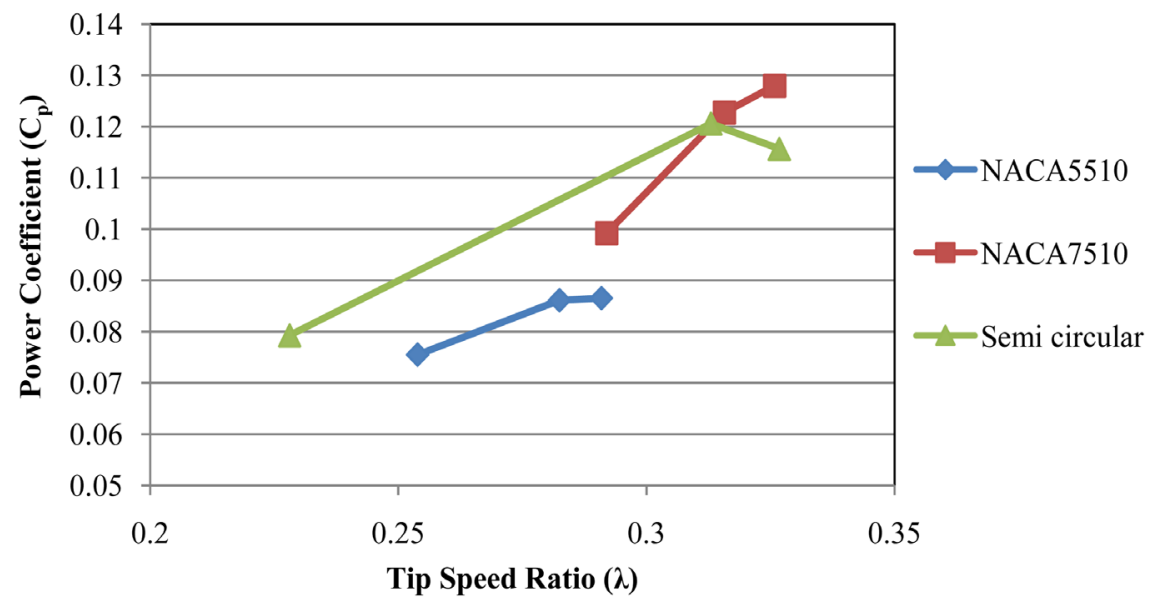

Figure 31. Experimental power coefficient $\left(C_{P}\right)$ vs. tip speed ratio $(\lambda)$ for three different three bladed models. 


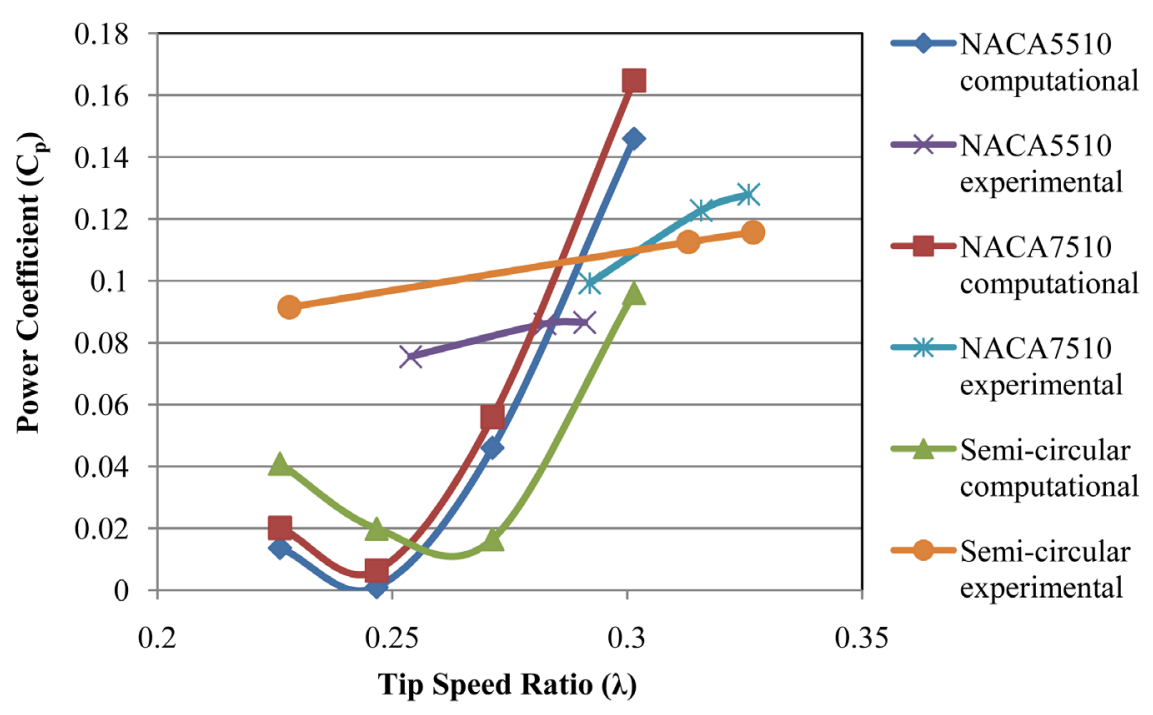

Figure 32. Power coefficient $\left(C_{P}\right)$ vs. tip speed ratio $(\lambda)$ from both numerical and experimental results for NACA5510, NACA7510, and semi-circular models.

experimentally and numerically when the tip speed ratio is relatively high. Experimentally, the semicircular one yields a very good coefficient curve as well. However, the numerical value of the power coefficient for the semicircular one is lower than the other models when the tip speed ratio is greater than 0.27 .

\subsection{Error Analysis}

Numerical and experimental values for both torque and power coefficients have been compared. It has been observed that the experimental results were somewhat different from the numerical ones. Human error and equipment related errors could have caused the relatively lower values of torque and power coefficients in the experimental approach. In the numerical approach, errors may have occurred mainly due to the assumptions that were taken as part of model simplification for analysis purpose.

\section{Conclusion}

Based on both computational and experimental results, several conclusions were made. Overall NACA 7510 yielded the best performance among all the models based on both numerical and experimental methods. Though NACA 5510 has the highest torque coefficient numerically and the semicircular model has a higher torque coefficient than both NACA models experimentally at a tip speed ratio less than 0.32 . Power coefficient in general increases as the tip speed ratio increases. At a high tip speed ratio, NACA 7510 shows the best performance considering both numerical and experimental data. However, the numerical study shows that NACA 5510 yields a higher power coefficient than the others at a given TSR; but it produces a lower power coefficient than the semi-circular model and NACA 7510 at a given TSR. Numerically, both torque and power coefficients are generally low below a TSR value of 0.25 ; however, passed this value these coefficients increase for most models. Numerical analysis shows that 
the drag coefficient increases as the TSR increases and NACA 5510 provides the highest drag coefficient among all models at a given TSR. For the lift coefficient based on the numerical method, all but the semicircular model have increasing trends against TSR and NACA 7510 has the best lift coefficient at a high value of TSR. It is apparent in this study that the aero-foil cambers affect the overall VAWT performance, i.e. by changing the camber percentage would directly affect drag and lift coefficients, torque coefficient, and power coefficient in varying amounts. In general, it is perceived from this study that an aero-foil based VAWT provides better performance as compared to a circular one.

\section{Acknowledgements}

The authors acknowledge the support from the Mechanical Engineering Department of Georgia Southern University. They would also like to thank Mr. Andrew Michaud, the Laboratory Supervisor of the Manufacturing Department, for helping in fabricating different wind turbine models.

\section{References}

[1] Reigler, H. (2011) HAWT versus VAWT.

http://www.booneyliving.com/546/advantages-and-disadvantages-of-the-vertical-ax is-wind-turbine-design/

[2] Ragheb, M. (2015) Wind Energy Converters Concepts. http://www.ragheb.co/NPRE\%20475\%20Wind\%20Power\%20Systems/Vertical\%20 Axis\%20Wind\%20Turbines.pdf

[3] Bishop, J.D.K. and Amartunga, G.A.J. (2008) Evaluation of Small Wind Turbines in Distributed Arrangement as Sustainable Wind Energy Oprtion for Barbados. Energy Conversion and Management, 49, 1652-1661. https://doi.org/10.1016/j.enconman.2007.11.008

[4] Islam, M., Ting, D.S.K. and Fartaj, A. (2008) Aerodynamic Models for DarrieusType Straight Bladed Vertical Axis wind Turbines. Renewable and Sustainable Energy Reviews, 12, 1087-1109. https://doi.org/10.1016/j.rser.2006.10.023

[5] Mohamed, M.H., Janiga, G, Pap, E. and Thevenin, D. (2011) Optimal Blade Shape of a Modified Savonius Turbine Using an Obstacle Shielding the Returning Blade. Energy Conversion and Management, 52, 236-242. https://doi.org/10.1016/j.enconman.2010.06.070

[6] Gupta, R., Das, R., Gautam, R. and Deka, S.S. (2012) CFD Analysis of a Two Bucket Savonius Rotor for Various Overlap Conditions. ISESCO Journal of Science and Technology, 8, 67-74.

[7] Morshed, K.N. (2010) Experimental and Numerical Investigations on Aerodynamic Characteristics of Savonius Wind Turbine with Various Overlap Ratios. Georgia Southern University, Statesboro.

[8] Qasim, A.Y., Usubamatov, R. and Zain, Z.M. (2011) Investagation and Design Impeller Type Vertical Axis Wind Turbine. Australian Journal of Basic and Applied Sciences, 5, 121-126.

[9] Manzoor, H.M., Nawazish Mehdi, S. and Ram Reddy, P. (2008) CFD Analysis of Low Speed Vertical Axis Wind. International Journal of Applied Engineering Research 3-1 (2008): 149-159.

[10] Ghatage, S.V. and Joshi, J.B. (2012) Optimisation of Vertical Axis Wind Turbine: 
CFD Simulations and Experimental Measurements. The Canadian Journal of Chemical Engineering, 90, 1186-1201. https://doi.org/10.1002/cjce.20617

[11] Kumbernuss, J., Chen, J., Yang, H.X. and Lu, L. (2012) Investigation into the Relationship of the Overlap Ratio and Shift Angle of Double Stage Three Bladed Vertical Axis Wind Turbine (VAWT). Journal of Wind Engineering and Industrial Aerodynamics, 107, 57-75. https://doi.org/10.1016/j.jweia.2012.03.021

[12] Saha, U.K., Thotla, S. and Maity, D. (2007) Optimum Design Configuration of Savonius Rotor through Wind Tunnel Experiments. Journal of Wind Engineering and Industrial Aerodynamics, 96, 1359-1375. https://doi.org/10.1016/j.jweia.2008.03.005

[13] Rahman, M., Morshed, K. and Ahmed, M.K. (2010) Numerical and Wind Tunnel Investigation on Aerodynamic Coefficients of a Three Bladed Savonius Wind Turbine with and without Overlap between Blades. Proceedings of the 2010 SAMPE Fall Technical Conference, Salt Lake City, 11-14 October 2010, 1-16.

[14] Morshed, K.N., Rahman, M., Molina, G. and Ahmed, M. (2013) Wind Tunnel Testing and Numerical Simulation on Aerodynamic Performance of a Three-Bladed Savonius Wind Turbine. International Journal of Energy and Environmental Engineering, 4, 4-18.

[15] Carrigan, T.J., Dennis, B.H., Han, Z.X. and Wang, B.P. (2012) Aerodynamic Shape Optimization of a Vertical-Axis Wind Turbine Using Differential Evolution. International Scholarly Research Network ISRN Renewable Energy, 2012, Article ID: 528418.

[16] Howell, R., Qin, N., Edwards, J. and Durrani, N. (2010) Wind Tunnel and Numerical Study of a Small Vertical Axis Wind Turbine. Renewable Energy, 35, 412-422. https://doi.org/10.1016/j.renene.2009.07.025

[17] Beri, H., and Yao, Y. (2011) Effect of Camber Airfoil on Self Starting of Vertical Axis Wind Turbine. Journal of Environmental Science and Technology, 4, 302-312.

[18] Hameed, M.S. and Kamran Afaq, S. (2012) Design and Analysis of a Straight Bladed Vertical Axis Wind Turbine Blade Using Analytical and Numerical Techniques. Ocean Engineering, 57, 248-255. https://doi.org/10.1016/j.oceaneng.2012.09.007

[19] Armstrong, S., Fiedler, A. and Tullis, S. (2012) Flow Separation on a High Reynolds Number, High Solidity Vertical Axis Wind Turbine with Straight and Canted Blades and Canted Blades with Fences. Renewable Energy, 41, 13-22. https://doi.org/10.1016/j.renene.2011.09.002

[20] Castelli, M.R., Monte, A.D., Quaresimin, M. and Benini, E. (2013) Numerical Evaluation of Aerodynamic and Inertial Contributions to Darrieus Wind Turbine Blade Deformation. Renewable Energy, 51, 101-112.

https://doi.org/10.1016/j.renene.2012.07.025

[21] Gupta, R., Biswas, A. and Sharma, K.K. (2008) Comparative Study of a ThreeBucket Savonius Rotor with a Combined Three-Bucket Savonius-Three-Bladed Darrieus Rotor. Renewable Energy, 33, 1974-1981.

https://doi.org/10.1016/j.renene.2007.12.008

[22] Patankar S.V. (1980) Numerical Heat Transfer and Fluid Flow. Hemisphere Publishing Corporation, Washington DC.

[23] Launder, B.E. and Spalding, D.B. (1972) Lectures in Mathematical Models of Turbulence. Academic Press, Waltham. 


\section{Nomenclature}

$\begin{array}{ll}A & \text { Rotor area }\left(\mathrm{m}^{2}\right) \\ D & \text { Overall rotor diameter }(\mathrm{mm}) \\ d & \text { Blade diameter }(\mathrm{mm}) \\ H & \text { Rotor height }(\mathrm{mm}) \\ \theta & \text { Rotor angle }\left(^{\circ}\right) \\ V & \text { Wind velocity, } \mathrm{m} / \mathrm{s} \\ N & \text { Rotational speed, } \mathrm{rpm} \\ v & \text { Kinematic viscosity of air, } \mathrm{m}^{2} / \mathrm{s} \\ \rho & \text { Air density, } \mathrm{kg} / \mathrm{m}^{3} \\ \omega & \text { Angular velocity, rad } / \mathrm{sec} \\ R e & \text { Reynolds Number } \\ \lambda & \text { Tip speed ratio }(\mathrm{TSR}) \\ T & \text { Torque (N.m) } \\ P & \text { Power (Watt) } \\ F_{l} & \text { Lift force } \\ F_{d} & \text { Drag force } \\ C_{d} & \text { Drag coefficient } \\ C_{l} & \text { Lift coefficient } \\ C_{q} & \text { Torque coefficient } \\ C_{p} & \text { Power coefficient }\end{array}$

Submit or recommend next manuscript to OALib Journal and we will provide best service for you:

- Publication frequency: Monthly

- 9 subject areas of science, technology and medicine

- Fair and rigorous peer-review system

- Fast publication process

- Article promotion in various social networking sites (LinkedIn, Facebook, Twitter, etc.)

- Maximum dissemination of your research work

Submit Your Paper Online: Click Here to Submit

Or Contact service@oalib.com 